\title{
2D metal carbides and nitrides (MXenes) for energy storage
}

\author{
Babak Anasori, Maria R. Lukatskaya and Yury Gogotsi \\ A.J. Drexel Nanomaterials Institute and Department of Materials Science \& Engineering, \\ Drexel University, Philadelphia, PA 19104, USA \\ Correspondence to Y.G.: gogotsi@drexel.edu
}

((Web summary, 40 words))

More than twenty 2D carbides, nitrides and carbonitrides of transition metals (MXenes) have been synthesized and studied, and dozens more predicted to exist. Highly electrically conductive MXenes show promise in electrical energy storage, electromagnetic interference shielding, electrocatalysis, plasmonics and other applications.

\begin{abstract}
The family of 2D transition-metal carbides, carbonitrides and nitrides (collectively referred to as MXenes) has expanded rapidly since the discovery of $\mathrm{Ti}_{3} \mathrm{C}_{2}$ in 2011 . The materials reported to date always have surface terminations, such as hydroxyl, oxygen or fluorine, which impart hydrophilicity to their surfaces. About 20 different MXenes have been synthesized, and the structures and properties of dozens more have been theoretically predicted. The availability of solid solutions, control of surface terminations, and a recent discovery of multi-transition-metal layered MXenes offers the potential for synthesis of many new structures. MXenes' versatile chemistry renders their properties tunable for applications including energy storage, electromagnetic interference shielding, reinforcement for composites, water purification, bio- and gas-sensors, lubrication, and chemical, photoand electro-catalysis. Attractive electronic, optical, plasmonic and thermoelectric properties have also been shown. In this Review, we present the synthesis, structure and properties of MXenes, as well as their energy-storage and related applications, and an outlook for future research.
\end{abstract}

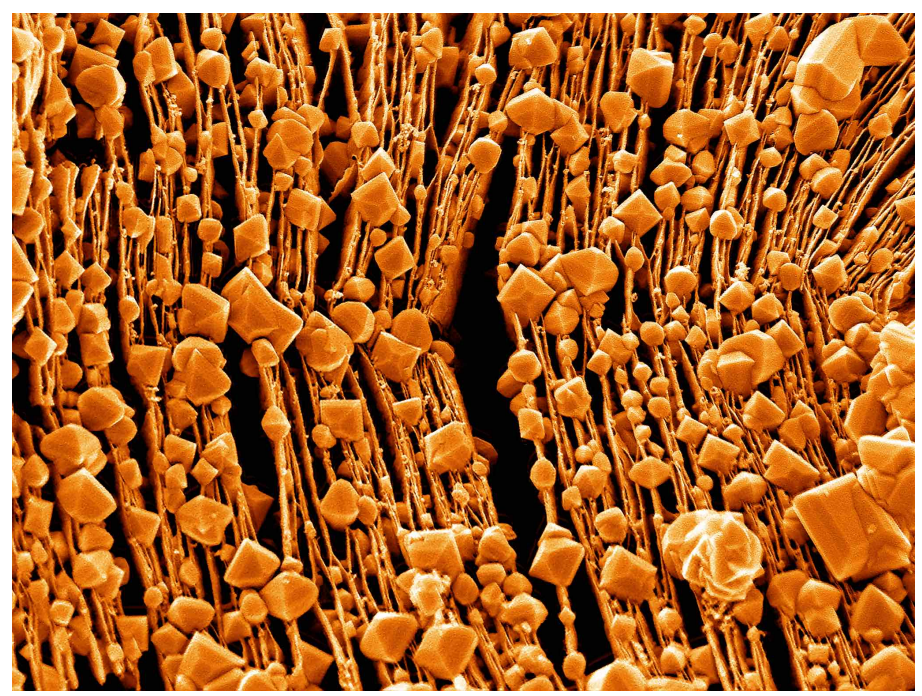

Cover Article, In Press. 
2D materials have unusual electronic, mechanical and optical properties ${ }^{1-6}$, which have led them to be extensively studied in the past decade for diverse applications. They can also serve as convenient building blocks for a variety of layered structures, membranes and composites ${ }^{7}$. Although several single-element 2D materials have been prepared, such as graphene, silicene ${ }^{8}$, germanene $e^{9,10}$ and phosphorene $e^{11,12}$, the majority contain two (for example, dichalcogenides and oxides) ${ }^{13,14}$ or more elements (for example, clays) ${ }^{1}$.

Transition metal carbides, carbonitrides and nitrides (MXenes) are among the latest additions to the $2 \mathrm{D}$ world ${ }^{15-21}$. Their general formula is $\mathrm{M}_{n+1} \mathrm{X}_{n} \mathrm{~T}_{x}(n=1-3)$, where $\mathrm{M}$ represents an early transition metal ( $\mathrm{Sc}, \mathrm{Ti}, \mathrm{Zr}, \mathrm{Hf}, \mathrm{V}, \mathrm{Nb}, \mathrm{Ta}, \mathrm{Cr}, \mathrm{Mo}$, and so on), $\mathrm{X}$ is carbon and/or nitrogen and $\mathrm{T}_{x}$ stands for the surface terminations (for example, $\mathrm{OH}, \mathrm{O}$ or $\mathrm{F}$ ) ${ }^{22}$. Some examples include $\mathrm{Ti}_{2} \mathrm{CT}_{\mathrm{x}}{ }^{16}, \mathrm{Ti}_{3} \mathrm{C}_{2} \mathrm{~T}_{\mathrm{x}}{ }^{15}$ and $\mathrm{Nb}_{4} \mathrm{C}_{3} \mathrm{~T}_{\mathrm{x}}{ }^{19}$. In MXenes, $n+l$ layers of $\mathrm{M}$ cover $n$ layers of $\mathrm{X}$ in an $[\mathrm{MX}]_{n} \mathrm{M}$ arrangement. Structures of $\mathrm{M}_{2} \mathrm{X}, \mathrm{M}_{3} \mathrm{X}_{2}$ and $\mathrm{M}_{4} \mathrm{X}_{3}$ are shown in FIG. $1 . \mathrm{Ti}_{3} \mathrm{C}_{2} \mathrm{~T}_{x}$ was the first MXene reported in $2011^{15}$, and 19 different MXene compositions have subsequently been synthesized (marked with blue in FIG. 1) with dozens more predicted to exist and studied in silico (marked with grey in FIG. 1) ${ }^{18,20,23,24}$. MXenes with more than one M element also exist in two forms: solid solutions and ordered phases. In the former, a random arrangement of two different transition metals is observed in the M layers (marked with green in FIG. 1). By contrast, in the ordered MXenes, single or double layers of one transition metal (for example, Ti) are sandwiched between the layers of a second transition metal (for example, Mo) in a 2D carbide structure (third row in FIG. 1). Density functional theory (DFT) calculations showed that for certain combinations of transition metals, ordered MXenes are energetically more stable than their solidsolution counterparts and more than 25 different ordered MXenes have been predicted ${ }^{20}$. These ordered compositions are marked in purple in FIG. 1. In addition to carbides, 2D transition metal carbonitrides (that is, $\mathrm{Ti}_{3} \mathrm{CN}$ ) ${ }^{16}$ and nitrides (that is, $\mathrm{Ti}_{4} \mathrm{~N}_{3}{ }^{25}$ were also reported, and there have been numerous predictions of the properties of nitrides, mostly from the $\mathrm{M}_{2} \mathrm{~N}$ family ${ }^{18,26-30}$.

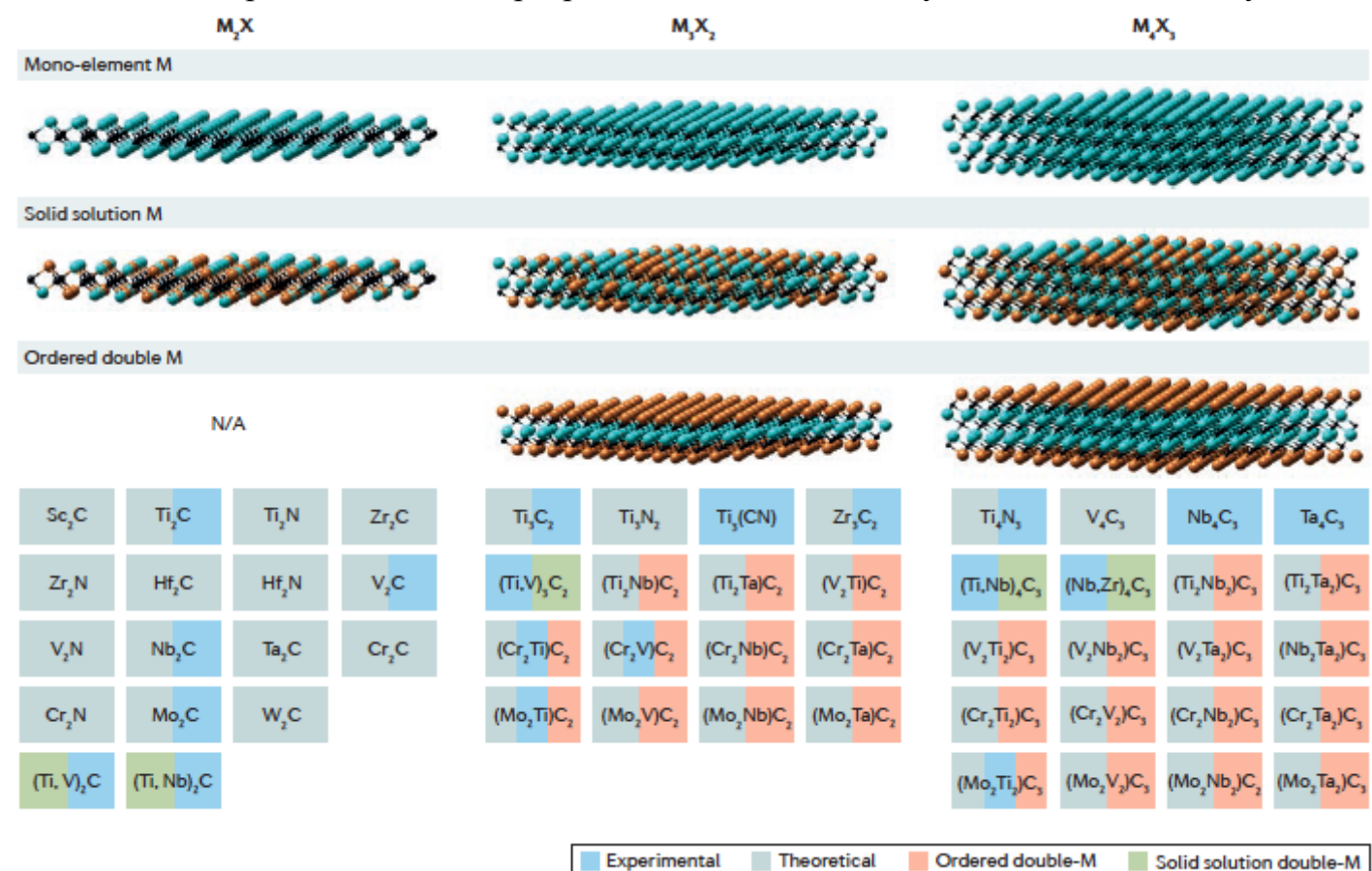

Figure 1 I MXenes reported to date. MXenes can have at least three different formulas, $M_{2} C, M_{3} C_{2}$ and $M_{4} C_{3}$, where $M$ is an early transition metal and $\mathrm{X}$ is $\mathrm{C}$ and/or $\mathrm{N}$. They can be made in three different forms: mono-M elements (for example, $\mathrm{Ti}_{2} \mathrm{C}, \mathrm{Nb}_{4} \mathrm{C}_{3}$ ); solid solution of at least two different $\mathrm{M}$ elements (for example, $\left.(\mathrm{Ti}, \mathrm{V})_{3} \mathrm{C}_{2},(\mathrm{Cr}, \mathrm{V})_{3} \mathrm{C}_{2}\right)$; or ordered double-M elements, in which one transition metal occupies the perimeter layers and another fills the central M layers (for example, $\mathrm{Mo}_{2} \mathrm{TiC}_{2}, \mathrm{Mo}_{2} \mathrm{Ti}_{2} \mathrm{C}_{3}$, in which the outer $\mathrm{M}$ layers are $\mathrm{Mo}$ and the central $\mathrm{M}$ layers are $\mathrm{Ti}$ ). Solid solutions on the $\mathrm{X}$ site produce carbonitrides. 


\section{Synthesis of MXenes}

MXenes are made by selective etching of certain atomic layers from their layered precursors, such as MAX phases. MAX phases are a very large family of ternary carbides and nitrides with more than 70 reported to date, in addition to numerous solid solutions and ordered double transition metal structures ${ }^{22,31-34}$. They are made of layers of transition metal carbides or nitrides $\left(\mathrm{M}_{n+1} \mathrm{X}_{n}\right)$ that are interleaved with layers of A-element atoms (mostly group 13 and 14 elements of the periodic table). A list of known MAX phases and their structures are provided in Supplementary information S1, table and figure. Because the M-A bond is metallic, it has not been possible to separate the $\mathrm{M}_{n+1} \mathrm{X}_{n}$ layers and make MXenes by mechanical shearing of MAX phases. However, $\mathrm{M}-\mathrm{A}$ bonds are more chemically active than the stronger $\mathrm{M}-\mathrm{X}$ bonds, which makes selective etching of A layers possible. Highly selective etching is the key condition for making MXenes.

Aqueous fluoride-containing acidic solutions have been predominantly used to selectively etch the A layers from MAX phases to synthesize MXenes (FIG. 2), either by using aqueous hydrofluoric acid (HF) ${ }^{22}$ or in situ formation of HF via a reaction of hydrochloric acid $(\mathrm{HCl})$ and fluoride (for example, lithium fluoride $(\mathrm{LiF}))^{35}$. Ammonium hydrogen bifluoride $\left(\mathrm{NH}_{4} \mathrm{HF}_{2}\right)$ and ammonium fluoride were also successfully applied for $\mathrm{Ti}_{3} \mathrm{C}_{2}$ synthesis from $\mathrm{Ti}_{3} \mathrm{AlC}_{2}{ }^{36-38}$. From about 10 different A elements of group 13 and 14 (Supporting information $\mathrm{S} 1$, table), only Al has been successfully etched from MAX phases to form MXenes.

It is also possible to synthesize MXenes from non-MAX phase precursors ${ }^{39-41} \cdot \mathrm{Mo}_{2} \mathrm{CT}_{x}$ is the first MXene of this kind that was made by etching Ga layers from $\mathrm{Mo}_{2} \mathrm{Ga}_{2} \mathrm{C}^{39,40}$. This phase, despite its similarity to MAX phases, has two A-element layers (Ga) separating the carbide layers. $\mathrm{Zr}_{3} \mathrm{C}_{2} \mathrm{~T}_{x}$ was synthesized from another non-MAX-phase precursor by selectively etching aluminium carbide $\left(\mathrm{Al}_{3} \mathrm{C}_{3}\right)$ layers from $\mathrm{Zr}_{3} \mathrm{Al}_{3} \mathrm{C}_{5}{ }^{41}$, instead of just the $\mathrm{Al}$ layers. $\mathrm{Zr}_{3} \mathrm{Al}_{3} \mathrm{C}_{5}$ belongs to a family of layered ternary transition metal carbides with general formulas of $\mathrm{M}_{n} \mathrm{Al}_{3} \mathrm{C}_{n+2}$ and $\mathrm{M}_{\mathrm{n}} \mathrm{Al}_{4} \mathrm{C}_{n+3}$, where $\mathrm{M}$ is a transition metal, typically $\mathrm{Zr}$ or Hf, and $n=1-3$. In these phases, a carbon layer separates each metal later. Thus, Al-C units, instead of A-element layers, separate the $\mathrm{M}_{2} \mathrm{C}$ or $\mathrm{M}_{3} \mathrm{C}_{2}$ layers ${ }^{42,43}$. It was recently shown that it is energetically more favourable to etch the Al-C units than just the $\mathrm{Al}$ layers in $\mathrm{Zr}_{3} \mathrm{Al}_{3} \mathrm{C}_{5}{ }^{41}$. This finding may enable the synthesis of new MXenes from non-MAX precursors, for example, by etching $\mathrm{Al}_{3} \mathrm{C}_{3}$ from $\mathrm{U}_{2} \mathrm{Al}_{3} \mathrm{C}_{4}{ }^{44}$ to form $\mathrm{U}_{2} \mathrm{CT}_{x}$ and other structures. Ultrathin $\mathrm{MoN}$ nanosheets have also been fabricated via liquid exfoliation of the bulk nitride ${ }^{45}$.

MXenes can also be made by high-temperature etching of MAX phases, as was recently demonstrated by treating $\mathrm{Ti}_{4} \mathrm{AlN}_{3}$ in a molten fluoride salt mixture at $550{ }^{\circ} \mathrm{C}$ under an argon atmosphere to form $\mathrm{Ti}_{4} \mathrm{~N}_{3}$ MXene ${ }^{25}$. Before the discovery of MXenes, gaseous etchants (halides) were used to etch MAX phases at elevated temperatures, but their selectivity was not sufficient and removed both $\mathrm{A}$ and $\mathrm{M}$ elements, leading to the formation of carbide-derived carbon ${ }^{46,47}$. There were also reports of high-temperature $\left(>800^{\circ} \mathrm{C}\right)$ removal of the A-element layers from MAX phases using molten salt ${ }^{48,49}$, and evaporating the A layer in a vacuum ${ }^{50}$. However, the resulting carbides were cubic, not $2 \mathrm{D}$, owing to the specific treatment conditions (for example, the temperature and gas environment). For example, in 2011, a layered titanium carboxyfluoride structure with cubic $\mathrm{TiC}_{x}$ layers was prepared by heating $\mathrm{Ti}_{3} \mathrm{AlC}_{2}$ in molten $\mathrm{LiF}$ in air at $900{ }^{\circ} \mathrm{C}^{51}$. This is in agreement with the transition metal carbide nonstoichiometric phase diagrams, in which ordered nonstoichiometric carbides (for example, $\mathrm{Ti}_{2} \mathrm{C}, \mathrm{Ti}_{3} \mathrm{C}_{2}$, which have similar formulae to MXenes) are stable below certain temperatures $\left(\sim 800^{\circ} \mathrm{C}\right)$ depending on the phase $\mathrm{s}^{52}$. Therefore, it is reasonable to assume that synthesis and annealing of MXenes must be performed below those temperatures and in a controlled atmosphere; otherwise, a cubic phase will form preferentially. Taken together, these results and the recent synthesis of $\mathrm{Ti}_{4} \mathrm{~N}_{3}$ MXene suggest that the molten-salt approach is effective for the synthesis of new MXenes.

Bottom-up synthesis methods, such as chemical vapour deposition (CVD), should also be possible for MXene synthesis ${ }^{21,53}$. In 2015, ultrathin (a few nanometres) $\alpha-\mathrm{Mo}_{2} \mathrm{C}$ orthorhombic 
2D crystals with up to $100-\mu \mathrm{m}$ lateral size were produced by CVD from methane on a bilayer substrate of copper foil sitting on a molybdenum foil ${ }^{53}$. Using the same method, other transition metals, such as $\mathrm{W}$ and $\mathrm{Ta}$, were made into ultrathin $\mathrm{WC}$ and TaC crystals ${ }^{53}$. This method yields MXenes with a large lateral size and few defects, facilitating the study of their intrinsic properties $^{21,53}$. The synthesis of MXene monolayers with this method is still to be demonstrated and bottom-up synthesis options should be further explored.

We focus on wet etching in this Review, because this is the most widely used method to fabricate MXenes.

Etching with hydrofluoric acid

Various MXenes can be produced by HF etching, as shown in FIG. 2, from room temperature to $55^{\circ} \mathrm{C}$ by controlling the reaction time and $\mathrm{HF}$ concentration ${ }^{22,54}$. HF is a highly selective etchant that is even capable of selectively removing different polytypes of $\mathrm{SiC}^{55}$.

The etching conditions for Al-containing MAX phases (FIG. 2b) vary from one transition metal to another, depending on the material's structure, atomic bonding and particle size. Etching conditions for every MXene synthesized to date are provided in Supplementary information S2 (table). On the basis of experimental findings, increasing the atomic number of $\mathrm{M}$ requires a longer time and stronger etching. This can be related to $\mathrm{M}-\mathrm{Al}$ bonding ${ }^{22}-$ knowing that $\mathrm{M}-\mathrm{Al}$ bonding is metallic, we speculate that a larger number of $\mathrm{M}$ valence electrons requires stronger etching.

Etching is a kinetically controlled process and each MXene needs a different etching time to achieve complete conversion. Usually MXenes with larger $n$ in $\mathrm{M}_{n+1} \mathrm{C}_{n} \mathrm{~T}_{x}$ require stronger etching and/or a longer duration. For example, $\mathrm{Mo}_{2} \mathrm{Ti}_{2} \mathrm{AlC}_{3}(n=4)$ requires an etching time twice as long as its $n=3$ counterpart (that is, $\mathrm{Mo}_{2} \mathrm{TiAlC}_{2}$ ) under the same etching conditions ${ }^{20,56}$ (Supplementary information S2, table). In general, every MXene can be made under different etching conditions, which lead to different quality (concentration of defects and surface chemistry), as will be discussed in the following sections.

Etching in the presence of a fluoride salt

Instead of HF, a mixture of a strong acid and a fluoride salt can be used to synthesize MXenes ${ }^{35,40,57}$. $\mathrm{HCl}$ and $\mathrm{LiF}$ react to form $\mathrm{HF}$ in situ, which selectively etches the A atoms. Recently, using a mixture of $\mathrm{HF}$ and $\mathrm{LiCl}$, similar etching results were achieved, suggesting that the presence of protons and fluoride ions is a necessary condition for etching and MXene 'clay' formation ${ }^{58}$. Etching in the presence of a metal halide leads to intercalation of cations (for example, $\mathrm{Li}^{+}$) and water, which results in an increased spacing and thus weakened interaction between MXene layers. This is one of the advantages of this method over pure HF etching, because MXene can be delaminated with no additional step, simply after washing to a $\mathrm{pH}$ value of about 6 to achieve single- or few-layer flakes (for example, $\mathrm{Ti}_{3} \mathrm{C}_{2} \mathrm{~T}_{x}^{59}$ ), as we discuss in the following section.

\section{Delamination}

In general, delamination of any 2D material is a necessary step in exploring its properties in the 2D state. Because multilayered MXenes have two- to sixfold stronger interlayer interactions than that in graphite and bulk $\mathrm{MoS}_{2}{ }^{60}$, simple mechanical exfoliation provides a low yield of single layers. There are only two reports of Scotch tape exfoliation of multilayer MXene into single flakes ${ }^{61,62}$ and the remainder have been delaminated via intercalation (FIG. 2d). A complete list of MXene intercalants reported to date is presented in Supplementary information S2. MXenes can be intercalated with a variety of polar organic molecules, such as hydrazine, urea and dimethyl sulfoxide (DMSO), isopropylamine or large organic base molecules such as tetrabutylammonium hydroxide (TBAOH), choline hydroxide or $n$-butylamine ${ }^{63}$. MXene intercalation with these molecules, followed by mechanical vibration or sonication in water, leads to a colloidal solution of single- and few-layer MXenes. Filtering then results in freestanding MXene 'paper' (FIG. 2d) 20,63-65.

MXenes (for example, $\mathrm{Ti}_{3} \mathrm{C}_{2} \mathrm{~T}_{x}$ ) can be intercalated with different metal cations, using 
aqueous solutions of ionic compounds, such as halide salts or metal hydroxides ${ }^{58,66}$. When etching with a fluoride salt mixed with an acid (for example, $\mathrm{HCl}$ and $\mathrm{LiF}$ ), no additional molecule is needed, because etched MXene is intercalated with metal cations (Supplementary information S2 (table)). In-situ delamination of MXenes can be achieved by raising the $\mathrm{pH}$ to almost neutral and with very mild mechanical vibration (for example, by hand shaking the solution) ${ }^{67,68}$. In general, the resulting aqueous colloidal MXene suspensions are stable (FIG. 2d) and do not aggregate owing to the negative zeta potential of the MXene flakes ${ }^{69}$.

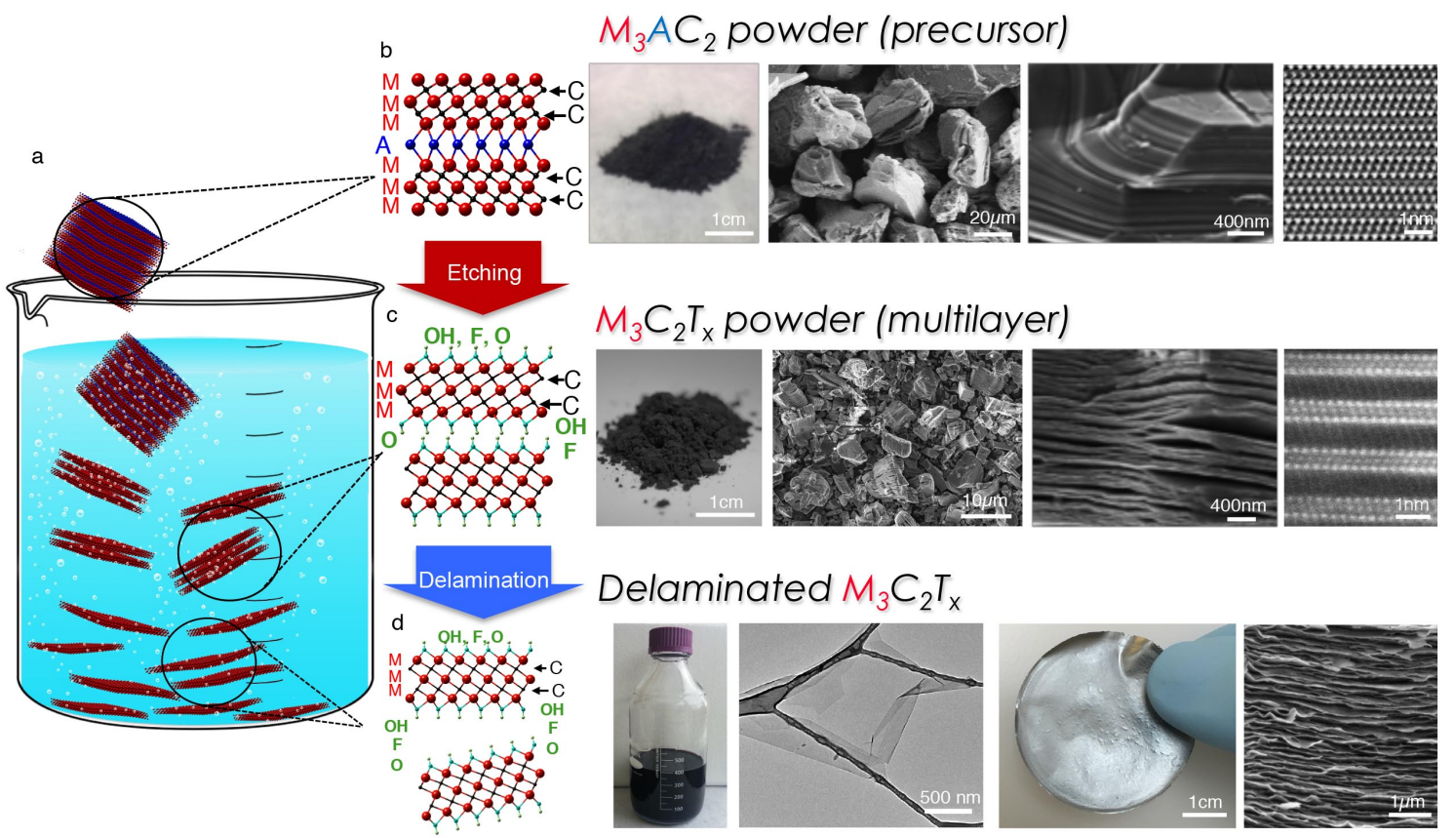

Figure 2 I Synthesis and characterization of MXenes. a I When a layered ternary carbide MAX powders $\left(M_{3} A I C_{2}\right.$ here $)$ is placed into a HF containing acidic aqueous solution (for example, HF or HCl-LiF), Al layer is selectively etched and replaced with $\mathrm{OH}, \mathrm{O}$ or $\mathrm{F}$ surface terminations $\left(\mathrm{T}_{x}\right)$, forming multilayer $\mathrm{M}_{3} \mathrm{C}_{2} \mathrm{~T}_{x} \mathrm{MXenes}$. Intercalation of water, cations, DMSO, TBAOH and so on into the interlayer spacing, followed by sonication makes it possible to delaminate MXenes to produce single flake suspensions. b I Images of MAX structures (for example, $\mathrm{M}_{3} \mathrm{AC}$ ). From left to right: schematic of the atomic structure, digital photograph of $\mathrm{Ti}_{3} \mathrm{AlC}_{2}$ powder, low magnification and higher magnification SEM images of $\mathrm{Ti}_{3} \mathrm{AlC}_{2}$, HR STEM image of $\mathrm{Mo}_{2} \mathrm{TiAIC}_{2}{ }^{20}$. c I Illustrations of multilayered MXene. From left to right: schematic of the atomic structure, digital photograph of $\mathrm{Ti}_{3} \mathrm{C}_{2} \mathrm{~T}_{x}$ powder, low magnification and higher magnification SEM images of $\mathrm{Ti}_{3} \mathrm{C}_{2} \mathrm{~T}_{x}, \mathrm{HR}$ STEM of $\mathrm{Mo}_{2} \mathrm{TiC}_{2} \mathrm{~T}_{x}^{20}$. d I Illustrations of delaminated MXene. From left to right: schematic of the atomic structure, digital photograph of $400 \mathrm{ml}$ of delaminated $\mathrm{Ti}_{3} \mathrm{C}_{2} \mathrm{~T}_{x}$ in water, digital photograph of a $\mathrm{Mo}_{2} \mathrm{TiC}_{2} \mathrm{~T}_{\mathrm{x}}$ film made by vacuum-assisted filtration, cross-sectional SEM image ${ }^{20}$ of a $\mathrm{Mo}_{2} \mathrm{TiC}_{2} \mathrm{~T}_{\mathrm{x}}$ film, TEM image of a single-layer $\mathrm{Ti}_{3} \mathrm{C}_{2} \mathrm{~T}_{x}$ flake. SEM, scanning electron microscope; HR STEM, high-resolution scanning transmission electron microscope; TEM, transmission electron microscope. HR STEM images in panels $\mathbf{b}$ and $\mathbf{c}$ and SEM of panel $\mathbf{d}$ adapted with permission from Ref. ${ }^{20}$, American Chemical Society.

\section{Structure and properties}

Structure of the MXene layer

Similar to their MAX precursors, $\mathrm{M}$ atoms in MXenes are arranged in a close-packed structure and $\mathrm{X}$ atoms fill the octahedral interstitial sites. Three packing arrangements are possible: $\mathrm{B} \gamma \mathrm{A}-$ $\mathrm{A} \gamma \mathrm{B}\left(\mathrm{M}_{2} \mathrm{X}-\mathrm{M}_{2} \mathrm{X}\right), \mathrm{B} \gamma \mathrm{A} \beta \mathrm{C}-\mathrm{C} \gamma \mathrm{A} \beta \mathrm{B}\left(\mathrm{M}_{3} \mathrm{X}_{2}-\mathrm{M}_{3} \mathrm{X}_{2}\right)$ and $\mathrm{B} \alpha \mathrm{C} \beta \mathrm{A} \gamma \mathrm{B}-\mathrm{B} \gamma \mathrm{A} \beta \mathrm{C} \alpha \mathrm{B}\left(\mathrm{M}_{4} \mathrm{X}_{3}-\mathrm{M}_{4} \mathrm{X}_{3}\right)$. Here, the capital Roman and Greek letters correspond to the $M$ and $X$ positions, respectively. The lowercase Greek letters represent the X octahedral interstitial sites corresponding to their Roman letter counterpart positions (that is, $\alpha, \beta$ and $\gamma$ correspond to A, B and C sites, respectively); Supplementary information S2 (figure). MXenes overall crystal is a hexagonal close packed structure. However, the ordering of $M$ atoms changes from $M_{2} X$ to $M_{3} X_{2}$ and $M_{4} X_{3}$. In $M_{2} X, M$ atoms follow $\mathrm{ABABAB}$ ordering (hexagonal close-packed stacking), whereas in $\mathrm{M}_{3} \mathrm{C}_{2}$ and $\mathrm{M}_{4} \mathrm{C}_{3}$, $\mathrm{M}$ atoms have $\mathrm{ABCABC}$ ordering (face-centred cubic stacking). This atomic ordering (see Supplementary information S2 (figure)) becomes very important for the synthesis of MXenes 
based on transition metals with hexagonal close-packed structures in the bulk state, such as Mo and $\mathrm{Cr}$ carbides. For example, $\mathrm{Mo}_{2} \mathrm{CT}_{x}$ is stable ${ }^{39,40}$ whereas $\mathrm{Mo}_{3} \mathrm{C}_{2} \mathrm{~T}_{x}$ and $\mathrm{Mo}_{4} \mathrm{C}_{3} \mathrm{~T}_{x}$, where $\mathrm{M}$ would be in the $\mathrm{ABCABC}$ ordering, are unstable ${ }^{20}$. The latter two have been stabilized by inserting another $\mathrm{M}$ element (for example, Ti) in the structure to form an ordered double transition metal $\mathrm{Mo}_{2} \mathrm{TiC}_{2} \mathrm{~T}_{x}$ and $\mathrm{Mo}_{2} \mathrm{Ti}_{2} \mathrm{C}_{3} \mathrm{~T}_{x}$ (FIG. 1$)^{20}$.

\section{Surface terminations}

MXenes synthesized using acidic fluoride-containing solutions have a mixture of $-\mathrm{OH}$, $\mathrm{O}$ and $-\mathrm{F}$ terminations, with the chemical formula $\mathrm{M}_{n+1} \mathrm{X}_{n}(\mathrm{OH})_{x} \mathrm{O}_{y} \mathrm{~F}_{z}$. For the sake of brevity, this is usually denoted as $\mathrm{M}_{n+1} \mathrm{X}_{n} \mathrm{~T}_{x}$, where $\mathrm{T}$ represents the surface terminations.

To date, non-terminated MXenes have not been synthesized. In most recent computational studies, surface terminations have been taken into account, in addition to evaluation of the properties of bare $\mathrm{M}_{n+1} \mathrm{X}_{n}$ layers ${ }^{23,27,70}$. Many studies have considered a specific surface termination (for example, pure $-\mathrm{OH},-\mathrm{O}$ or $-\mathrm{F}$ ) and predicted the MXenes' properties $^{18,24,71-85}$. Although it is possible to produce MXenes with specific terminations by postsynthesis processing, very few reports have appeared so far $^{62}$. MXenes with mixed terminations were also considered in two computational studies ${ }^{56,73}$.

The understanding of surface terminations is developing ${ }^{37,86-88}$. Schematics of their configurations are shown in Supplementary information S2 (figure). The configuration in which $\mathrm{T}$ is in a different atomic position to its neighbouring $\mathrm{M}$ and $\mathrm{X}$ atoms is predicted to be the most stable arrangement, creating ABCABC ordering for $\mathrm{M}, \mathrm{X}$ and $\mathrm{T}$, respectively ${ }^{18,22,24,28,74,76,78,89,90}$. There are some exceptions, in which $\mathrm{T}$ atoms are predicted to be right on top of the neighbouring $\mathrm{X}$ atoms in order to gain more electrons ${ }^{18,74,91,92}$.

The surface terminations and flake stacking of $\mathrm{Ti}_{3} \mathrm{C}_{2} \mathrm{~T}_{x}$ and $\mathrm{V}_{2} \mathrm{CT}_{x}$, among all MXenes, were recently studied by electron energy-loss spectroscopy in transmission electron microscopy ${ }^{37,86}$, neutron scattering ${ }^{87}$, and nuclear magnetic resonance (NMR) spectroscopy ${ }^{93,94}$. These studies confirmed that there is a random distribution of terminations on MXene layers, rather than regions terminated by a certain kind of atom or group ${ }^{87,94}$, with ordering arrangements in agreement with DFT predictions, as discussed earlier; $\mathrm{OH}$ and $\mathrm{F}$ are directly bonded to the surface of MXene flakes and water is hydrogen bonded to the $\mathrm{OH}$ groups ${ }^{93}$. Also, there are no neighbouring $-\mathrm{OH}$ terminations ${ }^{94}$. These studies provided a realistic map of surface terminations on $\mathrm{Ti}_{3} \mathrm{C}_{2}$ sheets that can be used for predicting their properties by DFT.

Based on neutron scattering measurements on $\mathrm{Ti}_{3} \mathrm{C}_{2} \mathrm{~T}_{x}$, it was suggested that interactions between the layers can be described by (i) hydrogen bonding between $\mathrm{O}$ or $\mathrm{F}$ atoms of one surface with the $\mathrm{OH}$ surface groups of the opposing $\mathrm{Ti}_{3} \mathrm{C}_{2} \mathrm{~T}_{x}$ sheet, and (ii) van der Waals bonding of $\mathrm{O}$ and/or $\mathrm{F}$ atoms between the sheets. The extent of interlayer hydrogen bonding depends not only on the orientation of the $\mathrm{OH}$ groups relative to the layers, but also on the amount and distribution of $-\mathrm{OH}$ relative to the $-\mathrm{O}$ and $-\mathrm{F}$ moieties positioned on the opposing surface ${ }^{87}$. When water is present between the layers, it hydrogen bonds strongly with $\mathrm{O} / \mathrm{OH}$ terminations ${ }^{88,95}$. Moreover, intercalation of cations can lead to easy sliding of the $\mathrm{Ti}_{3} \mathrm{C}_{2} \mathrm{~T}_{x}$ sheets relative to each other ${ }^{86}$, altering their rheological properties and leading to clay-like behaviour.

\section{Effect of synthesis conditions on MXene quality and terminations}

As-synthesized MXene flakes contain intrinsic defects such as atomic vacancies and adatoms $^{37,67}$. Etching and delamination conditions affect the quality, overall crystallinity, defects and surface functionalization in MXene flakes, as well as their delamination efficiency. In general, milder etching and delamination conditions produce larger MXene flakes with lower defect concentrations (FIG. 3a-e) $)^{40,59,67,87,96}$. Single metal vacancies or vacancy clusters were observed in $\mathrm{Ti}_{3} \mathrm{C}_{2} \mathrm{~T}_{x}$ flakes synthesized even under very mild conditions (FIG. $3 \mathrm{f}-\mathrm{h}$ ), and their concentration is highly dependent on the HF concentration used during etching of the carbide precursor (FIG. 3i) ${ }^{67}$. $\mathrm{Ti}_{3} \mathrm{C}_{2} \mathrm{~T}_{x}$ flakes of 3-6- $\mu \mathrm{m}$ lateral size with minimal defects have been 
produced via mild delamination (FIG. $3 \mathrm{c}, \mathrm{e})^{59,68,97}$. Sonication of these flakes in water reduces their lateral size to less than $1 \mu \mathrm{m}$ and increases the concentration of defects (FIG. $3 \mathrm{~b}, \mathrm{~d})^{59,97}$. The etching temperature and time are also important. For example, when synthesizing $\mathrm{Ti}_{3} \mathrm{C}_{2} \mathrm{~T}_{x}$ in $\mathrm{HCl}$ and $\mathrm{LiF}$, a higher etching temperature and longer etching time can lead to complete conversion to MXene, but can also reduce the delamination yield and quality of flakes owing to a higher concentration of defects ${ }^{35}$.

Scanning electron microscopy images of $50 \%$ HF-etched $\mathrm{Ti}_{3} \mathrm{C}_{2} \mathrm{~T}_{x}$ reveal accordion-like particles (Supplementary information, FIG. S3a), whereas etching in $\mathrm{HCl}$ and LiF produces densely packed particles (Supplementary information, FIG. S3b) owing to milder etching accompanied by $\mathrm{Li}^{+}$intercalation ${ }^{94}$. In agreement with this observation, it was shown that intercalation of metal cations can change the HF-etched $\mathrm{Ti}_{3} \mathrm{C}_{2} \mathrm{~T}_{x}$ morphology to thicker multilayer lamellas with fewer inter-stack gaps ${ }^{66}$. However, it is important to note that this is a result of the particles' morphology and does not imply that 50\% HF-etched MXene atomic layers are more separated. In fact, the distance between MXene layers of the as-etched MXene in $\mathrm{HCl}$ and $\mathrm{LiF}$ (cations and water intercalated) is about $2.8 \AA$ larger than that of the 50\% HF-etched MXene; this is because of the presence of a layer of water with cations between the MXene layers in the former case ${ }^{58,66,94}$. In general, MXene interlayer spacing depends on the number of intercalated water molecules between the MXene layers, as described in FIG. S3c of the Supplementary information.
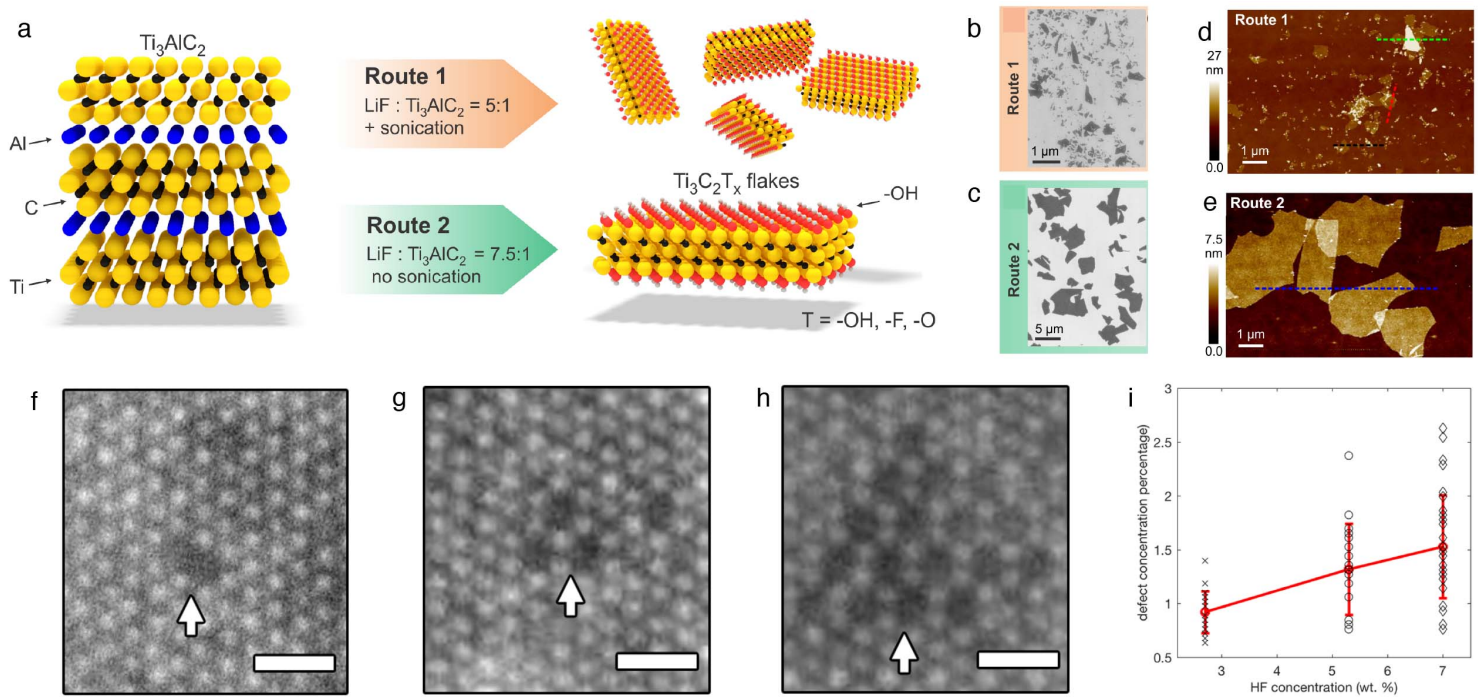

Figure 3 I Effect of synthesis conditions on MXene. a I Synthesis of $\mathrm{Ti}_{3} \mathrm{C}_{2} \mathrm{~T}_{x}$ via two different routes using $\mathrm{LiF}-\mathrm{HCl}$ as the etching solution. In route 1, a lower concentration of LiF and delaminating with sonication gives smaller MXene flakes. In route 2, increasing the concentration of LiF and delaminating with 5 minute hand shaking. $\mathbf{b}, \mathbf{c}$ I TEM images of the of $\mathrm{Ti}_{3} \mathrm{C}_{2} \mathrm{~T}_{x}$ flakes from (b) route 1 and (c) route 2. d, e I Atomic force microscopy images of $\mathrm{Ti}_{3} \mathrm{C}_{2} \mathrm{~T}_{x}$ flakes deposited on a $\mathrm{Si} / \mathrm{SiO}_{2}$ substrate by (d) route 1 and $(\mathbf{e})$ route 2 . $\mathbf{f}-\mathbf{h}$ I High-angle annular dark field scanning transmission electron microscopy (HAADF-STEM) images of vacancy clusters in HCl-LiF etched single-layer $\mathrm{Ti}_{3} \mathrm{C}_{2} \mathrm{~T}_{x}$ flakes: (f) two adjacent titanium vacancies forming within two different sublayers, (g) three titanium vacancies within the same sublayer, (h) seventeen titanium vacancies within the same sublayer. Scale bars are $0.5 \mathrm{~nm}$. i I Scatter plot of defect concentration from images acquired from samples produced using different HF concentrations. The red line shows the error plot with the average and standard deviation for different HF concentration. TEM, transmission electron microscope. Panels a-e adapted with permission from Ref. ${ }^{59}$, Wiley- $\mathrm{VCH}$. Panels $\mathbf{f}, \mathbf{g}, \mathbf{h}$ and $\mathbf{i}$ from Ref. ${ }^{67}$, American Chemical Society.

$\mathrm{V}-, \mathrm{Nb}-$, Ta- and Mo-containing MXenes require more aggressive etching conditions. To date, they have primarily been etched using $\sim 50 \% \mathrm{HF}$ and delaminated either by DMSO or $\mathrm{TBAOH}^{40,56,65}$. However, all MXenes can be produced using acid with a metal fluoride salt mixture (for example, $\mathrm{HCl}-\mathrm{LiF}$ ), when the etching conditions are optimized. For example, $\mathrm{Mo}_{2} \mathrm{CT}_{x}$ etched with $50 \% \mathrm{HF}$ and delaminated using $\mathrm{TBAOH}$, can also be etched and delaminated using $\mathrm{HCl}-\mathrm{LiF}^{40,57}$. Although the resulting MXene colloidal solution concentration 
in the former method is much higher than the latter, the MXene flakes are larger with fewer defects for the $\mathrm{HCl}-\mathrm{LiF}$ method owing to the milder etching conditions ${ }^{40}$. Reducing the etching time and bubbling with argon during the process are important measures for preventing oxidation, over-etching and the formation of defects.

Surface terminations depend on the etching and delamination conditions, type of $\mathrm{M}$ element and post-synthesis treatment and storage ${ }^{88,94}$. Different concentrations of HF give different surface termination ratios ${ }^{87}$. In general, lower $\mathrm{HF}$ concentrations result in a larger $\mathrm{O}$ to $\mathrm{F}$ ratio. For example $\mathrm{Ti}_{3} \mathrm{C}_{2} \mathrm{~T}_{x}$, when etched using less concentrated $\mathrm{HF}$ solutions (that is, $10 \% \mathrm{HF}^{87}$ and $\mathrm{HCl}-\mathrm{LiF}^{94}$ ), has more oxygen and less fluorine compared with MXene samples synthesized using 50\% HF (Supplementary information, FIG. S3d). Moreover, different etching solutions affect the surface chemistry of MXenes. For example, etching $\mathrm{Ti}_{3} \mathrm{AlC}_{2}$ with $\mathrm{NH}_{4} \mathrm{HF}_{2}$ and $\mathrm{HCl}-$ $\mathrm{LiF}$ results in the intercalation of $\mathrm{NH}_{4}^{+}$and $\mathrm{Li}^{+}$cations, respectively ${ }^{58}$.

Further insight into the surface terminations was provided by X-ray photoelectron spectroscopy (XPS), which revealed that $\mathrm{Ti}_{3} \mathrm{C}_{2} \mathrm{~T}_{x}$ oxidizes upon storage in air and that fluorine is slowly replaced by $-\mathrm{O}$; these findings were in agreement with theoretical calculations ${ }^{71}$. This is noteworthy because oxygen-terminated MXenes are predicted to have higher capacity in Li-ion and other batteries ${ }^{71}$, which will be discussed later. However, NMR studies show that the termination groups remained the same after drying at $200{ }^{\circ} \mathrm{C}$ in vacuum and that only the content of intercalated water was reduced. There are therefore discrepancies between the content of each termination measured with these two techniques (for example, the $-\mathrm{OH}$ content measured by NRM is very small ${ }^{94}$, whereas it is relatively large according to the XPS results ${ }^{88}$. These discrepancies could stem from a multitude of factors, including NMR providing averaged data on terminations in contrast to the surface-sensitive XPS, or possible variations in sample preparation and storage. It is important that this be clarified both experimentally and computationally.

\section{Stability}

Single MXene flakes are not indefinitely stable in environments with oxygen and water present $^{98}$. However, they are relatively stable in oxygen-free degassed water or in dry air. Also, exposure to light can accelerate the oxidation of colloidal MXene solutions. Therefore, it is recommended to store MXene colloids refrigerated in an oxygen-free dark environment. In general, oxidation of MXene flakes starts from the edges, leading to the formation of metal oxide nanocrystals (for example, $\mathrm{TiO}_{2}$ ) decorating the flake edges, and then develops via nucleation and growth throughout the entire surface ${ }^{99-101}$. The stability of MXene flakes depends on the manufacturing procedure: higher-quality single flakes of MXene have higher stability ${ }^{59}$.

The understanding of high-temperature stability of MXenes is still developing. Phase diagrams of nonstoichiometric transition metal carbides may help to predict the phase stability of MXenes $^{52}$. High-temperature stability of MXenes dependens on their composition and the environment. Consequently, different studies have reported different high temperature behaviour. Recently, it was shown that $\mathrm{Ti}_{3} \mathrm{C}_{2} \mathrm{~T}_{x}$ is stable at $500{ }^{\circ} \mathrm{C}$ in an $\mathrm{Ar}$ atmosphere, but some $\mathrm{TiO}_{2}$ crystals form, decorating the edges of the particles ${ }^{99}$. Moreover, the $\mathrm{Ti}_{3} \mathrm{C}_{2}$ structure was preserved even at $1200{ }^{\circ} \mathrm{C}$ under Ar and defect annealing occurred. However, XRD results indicated MXene phase transformation by having strong peaks of cubic $\mathrm{TiC}_{x}$, which is the most stable phase at $1200{ }^{\circ} \mathrm{C}$ in the nonstoichiometric TiC phase diagram ${ }^{52}$. Temperature-programmed desorption with mass spectroscopy showed substantial weight loss of $\mathrm{Ti}_{3} \mathrm{C}_{2} \mathrm{~T}_{x}$ above $800{ }^{\circ} \mathrm{C}$ in a He atmosphere ${ }^{95}$, indicating a phase transformation, which is in agreement with vacuum calcination treatment at the same temperature ${ }^{102}$ and in-situ TEM observations ${ }^{103} . \mathrm{Ti}_{2} \mathrm{CT}_{x}$ is confirmed to be stable at $250{ }^{\circ} \mathrm{C}$ under different inert atmospheres ${ }^{101}$. However, in a different study, $\mathrm{Ti}_{2} \mathrm{CT}_{x}(\mathrm{~T}=\mathrm{O})$ was shown to be stable at $1100{ }^{\circ} \mathrm{C}$ in $\mathrm{Ar} / \mathrm{H}_{2}{ }^{62}$, which is above the phase stability limit of nonstoichiometric $\mathrm{Ti}_{2} \mathrm{C}$. Although the characterization results are convincing, XRD or detailed Raman analysis is needed to confirm whether any new phases are formed. $\mathrm{Zr}_{3} \mathrm{C}_{2} \mathrm{~T}_{x}$ was shown to have good thermal stability and retain its $2 \mathrm{D}$ nature at temperatures up to $1000{ }^{\circ} \mathrm{C}$ under vacuum, in contrast to 
$\mathrm{Ti}_{3} \mathrm{C}_{2} \mathrm{~T}_{x}$, which transforms to cubic carbide. The better thermal stability of $\mathrm{Zr}_{3} \mathrm{C}_{2}$ can be explained by its structure being more energetically favourable than bulk $\mathrm{ZrC}$, in contrast to $\mathrm{Ti}_{3} \mathrm{C}_{2}$, which is metastable relative to bulk cubic $\mathrm{TiC}^{41}$. Thanks to its higher stability, $\mathrm{Zr}_{3} \mathrm{C}_{2} \mathrm{~T}_{x}$ may be useful for high-temperature applications.

Attempts to synthesize $\mathrm{Cr}_{2} \mathrm{C}$ from $\mathrm{Cr}_{2} \mathrm{AlC}$ were unsuccessful so far ${ }^{104}$. One possible explanation is the lower stability of chromium carbide due to its lower cohesive energy than other carbides $^{31}$. During etching, $\mathrm{Cr}_{2} \mathrm{C}$ possibly forms in the aqueous solutions and quickly transforms to other phases, such as chromium oxides.

Mechanical and physical properties

The rich transition metal chemistry of MXenes (FIG. 1) led to several computational studies investigating the effect of $\mathrm{M}, \mathrm{X}$ and $\mathrm{T}$, the number of $\mathrm{M}$ layers and lattice strain on MXenes' electronic, thermal and mechanical properties ${ }^{18,23,24,26,27,29,30,79,89,105-116}$.

Both $\mathrm{DFT}^{23}$ and molecular dynamics (MD) ${ }^{113}$ predict that $\mathrm{M}_{2} \mathrm{X}$ MXenes are stiffer and stronger than their $\mathrm{M}_{3} \mathrm{X}_{2}$ and $\mathrm{M}_{4} \mathrm{X}_{3}$ counterparts (FIG. 4a). However, experimental mechanical testing has only been conducted for MXene films and not for single-layer MXenes (FIG. 4b-d). A cylinder with walls made of a $5-\mu \mathrm{m}$-thick $\mathrm{Ti}_{3} \mathrm{C}_{2} \mathrm{~T}_{x}$ paper can support $\sim 4,000$ times its own weight (FIG. 4d). These films can be further strengthened by creation a $\mathrm{Ti}_{3} \mathrm{C}_{2} \mathrm{~T}_{x}$ composite with 10 -wt.\% polyvinyl alcohol (PVA) to hold $\sim 15,000$ times in their own weight ${ }^{117}$.
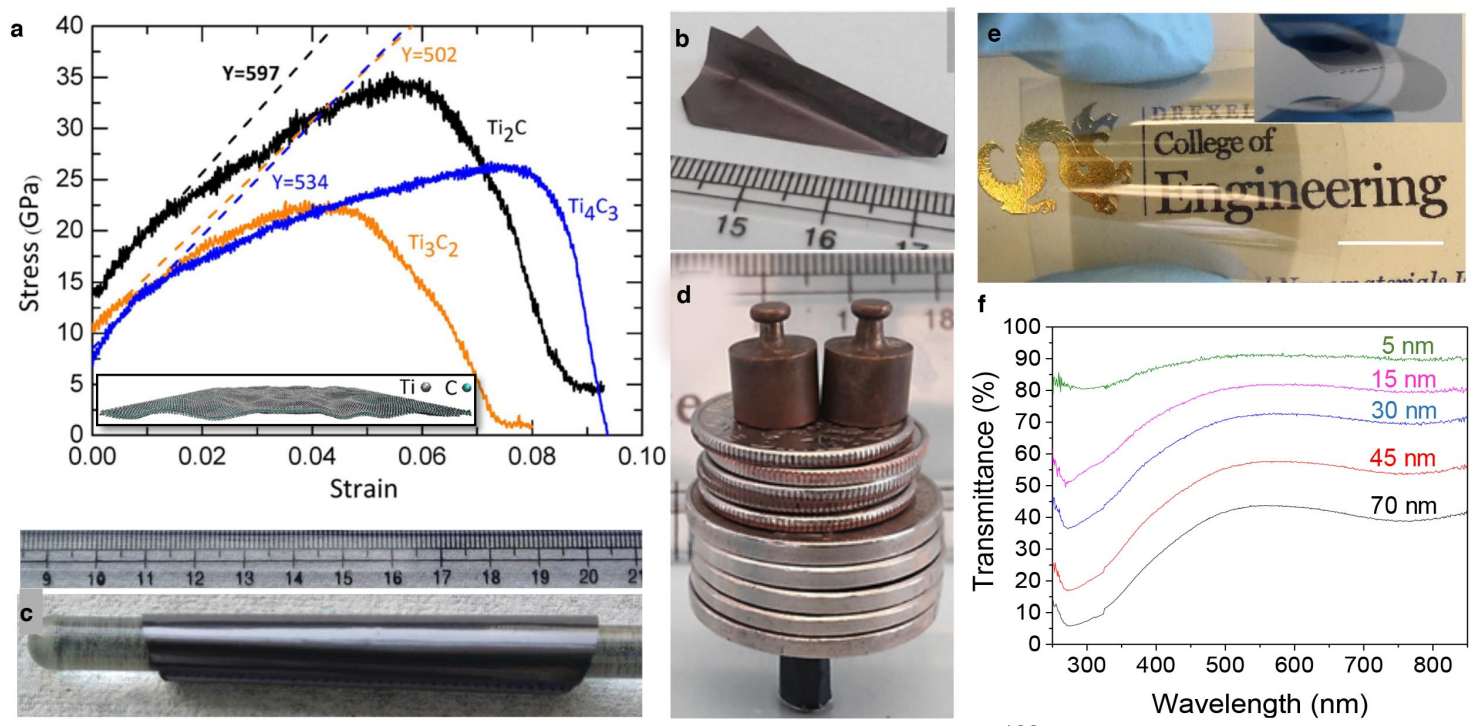

Figure 4 I Mechanical and optical properties of MXenes. a I Stress-strain curves calculated for the $\mathrm{Ti}_{n+1} \mathrm{C}_{n}$ samples during tensile loading using molecular dynamics (MD). The dashed lines are extrapolated from the initial linear regions of the stress-strain curves. The inset is a snapshot of $\mathbf{a ~ T i}_{2} \mathrm{C}$ sample after equilibration at $300 \mathrm{~K} . \mathbf{b}, \mathbf{c}$ I To demonstrate its flexibility, a $\mathrm{Ti}_{3} \mathrm{C}_{2} \mathrm{~T}_{x}$ film was folded into the shape of a paper airplane (b) and rolled onto a 10-cm-diameter glass rod (c). d I A hollow cylinder, made from a 3.9- $\mu$ m-thick strip of 90 wt. $\% \mathrm{Ti}_{3} \mathrm{C}_{2} \mathrm{~T}_{\mathrm{x}} / \mathrm{PVA}$ composite, can support about 15,000 times its own weight. The loads used were nickels $(5 \mathrm{~g})$, dimes $(2.27 \mathrm{~g})$, and 2.0-g weights. e I Optical image of spray-coated $\mathrm{Ti}_{3} \mathrm{C}_{2} \mathrm{~T}_{x}$ film on a flexible polyester substrate. The inset in (e) shows the bending of a $\mathrm{Ti}_{3} \mathrm{C}_{2} \mathrm{~T}_{x}$ film on the flexible substrate. The scale bar is $1 \mathrm{~cm}$. $f$ I UV-visible spectra of spray-coated $\mathrm{Ti}_{3} \mathrm{C}_{2} \mathrm{~T}_{\mathrm{x}}$ films with different thicknesses. Panel a adapted with permission from Ref. ${ }^{113}$, Institute of Physics. Panels $\mathbf{b}, \mathbf{c}, \mathbf{d}$ from Ref. ${ }^{117}$ of National Academy of Science. Panels $\mathbf{e}$ and $\mathbf{f}$ from Ref. ${ }^{125}$, Wiley-VCH.

Many MXene-polymer composites have been developed — for example, with PVA ${ }^{117}$, polypyrrole $^{118}$, polyethylene ${ }^{119}$ or polydimethylsiloxane (PDMS $)^{120}$ - with enhanced mechanical, thermal and electrochemical properties, and wear resistance. In a recent study, pyrrole monomer was mixed with $\mathrm{Ti}_{3} \mathrm{C}_{2} \mathrm{~T}_{x}$ colloidal solution and owing to the MXene's acidic properties, polymerization initiated without the need of oxidant to form a MXene-polypyrrole composite with high electrochemical capacitance ${ }^{118}$. In addition to polymers, MXene-carbon nanotube (CNT) hybrids have been prepared, mostly for electrochemical applications ${ }^{64,121-123}$. Recently, 
taking advantage of electrostatic forces (MXene flakes are negatively charged with a zeta potential of -30 to $-80 \mathrm{mV}^{65}$ ), self-assembled films have been made with positively charged particles, such as oxidized or surfactant-coated $\mathrm{CNTs}^{69}$.

Thin films of MXenes and their composites are transparent. $\mathrm{Ti}_{3} \mathrm{C}_{2}$ transmits $>97 \%$ of visible light per nanometre thickness ${ }^{124,125}$ (FIG. 4e,f), and its optoelectronic properties can be tuned by chemical and electrochemical intercalation of cations ${ }^{125}$. This suggests applications of MXene filmsin transparent conductive coating and optoelectronics.

Theoretical studies showed that the electronic properties of different MXenes range from metallic to semiconducting, depending on the nature of $\mathrm{M}, \mathrm{X}$ and the surface termination ${ }^{15,18,28-}$ 30,89,126. Some MXenes with heavier transition metals (that is, Cr, Mo and W) are predicted to be topological insulators ${ }^{92,109,127}$. Among all MXenes, only electronic properties of $\mathrm{Ti}_{2} \mathrm{C}, \mathrm{Ti}_{3} \mathrm{C}_{2}$, $\mathrm{Mo}_{2} \mathrm{C}, \mathrm{Mo}_{2} \mathrm{TiC}_{2}$ and $\mathrm{Mo}_{2} \mathrm{Ti}_{2} \mathrm{C}_{3}$ with mixed terminations have been experimentally measured $^{36,40,59,61,62,124,128}$. It has been shown that changing the outer $M$ layers can affect the electronic properties ${ }^{56,91}$. For example, whereas $\mathrm{Ti}_{3} \mathrm{C}_{2} \mathrm{~T}_{x}$ is metallic (FIG. 5a,c), the Mocontaining MXenes show semiconductor-like properties (FIG. 5b,d) and have a positive magnetoresistance at $10 \mathrm{~K}$ (FIG. 5e $)^{56,91}$. Post treatment that changes surface terminations can also change the transport properties of MXenes. For example, semiconductor-like behaviour of $\mathrm{Ti}_{2} \mathrm{CO}_{2}$ was observed after thermal annealing of $\mathrm{Ti}_{2} \mathrm{CT}_{x}$ at $1100^{\circ} \mathrm{C}$ under $\mathrm{Ar} / \mathrm{H}_{2}{ }^{62}$. Although these results agree with theoretical predictions ${ }^{126}, \mathrm{Ti}_{2} \mathrm{CT}_{x}$ could be partially transformed to other phases at this temperature. Thus, further studies are needed to understand the changes in MXene properties with temperature.

In addition of the composition, the electrical conductivity of MXenes depends on the sample preparation method. In general, a low concentration of defects and large flake size result in higher conductivity. This can be achieved through milder etching and sonication-free delamination $^{68}$, good contact between individual flakes by coplanar alignment ${ }^{124}$ and drying to remove intercalated species between the layers ${ }^{102}$. As a result, the conductivity of $\mathrm{Ti}_{3} \mathrm{C}_{2} \mathrm{~T}_{x}$ ranges from less than $1000 \mathrm{~S} \mathrm{~cm}^{-1}$ for cold-pressed disks made of highly defective HF-etched powder ${ }^{16,102}$ to 4,600 and $6,500 \mathrm{~S} \mathrm{~cm}^{-1}$ for milder etched and delaminated vacuum filtered ${ }^{68}$ and spincast films ${ }^{124}$, respectively; these values exceed those of other solution-processed materials, including graphene ${ }^{129,130}$.
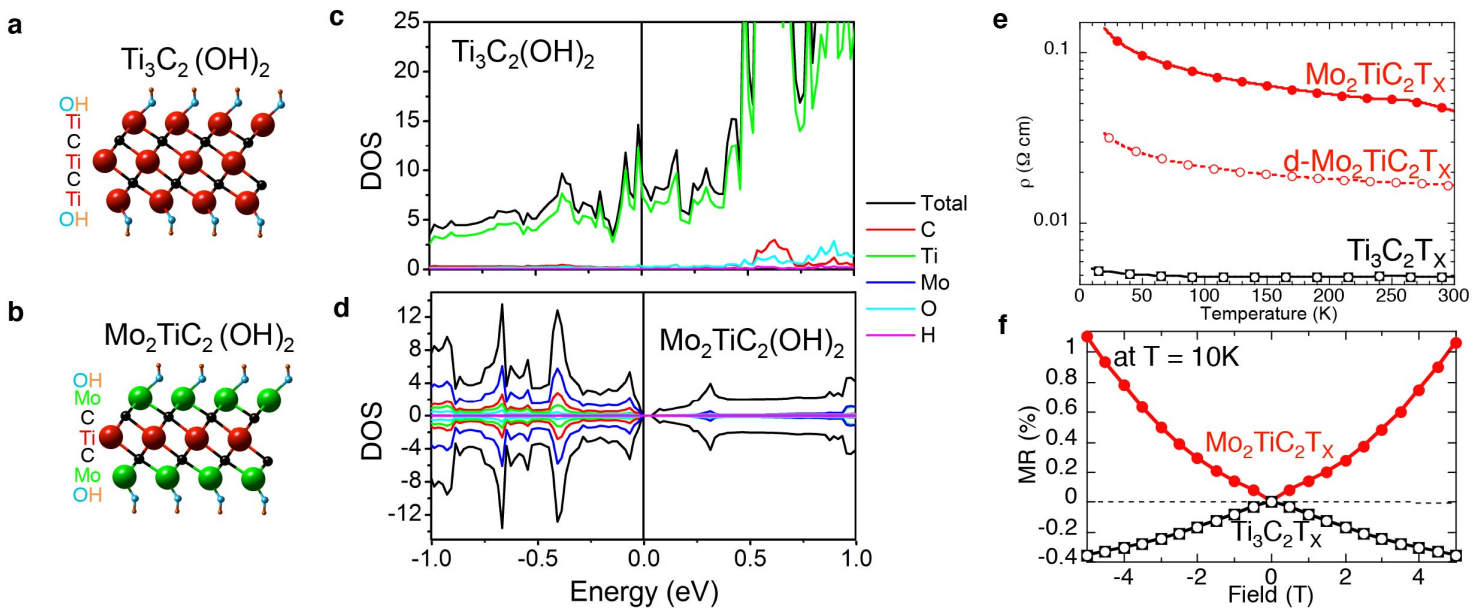

Figure 5 I Modification of the electronic properties of MXene by changing its outer $\mathbf{M}$ layers. $\mathbf{a}$, $\mathbf{b}$ I Schematics of $\mathrm{OH}$-terminated $\mathrm{Ti}_{3} \mathrm{C}_{2}$ and $\mathrm{Mo}_{2} \mathrm{TiC}_{2}$. c, d I Calculated density of states (DOS) of OH-terminated: (c) $\mathrm{Ti}_{3} \mathrm{C}_{2}$ and $(\mathbf{d}) \mathrm{Mo}_{2} \mathrm{TiC}_{2}$. Whereas the former is metallic, the latter is a narrow band-gap semiconductor. e I Temperature dependence of the resistivity for $\mathrm{Mo}_{2} \mathrm{TiC}_{2} \mathrm{~T}_{x}$ and $\mathrm{Ti}_{3} \mathrm{C}_{2} \mathrm{~T}_{x}$. The dashed lines represent delaminated films $\left(\mathrm{d}-\mathrm{Mo}_{2} \mathrm{TiC}_{2} \mathrm{~T}_{x}\right)$ and the solid lines correspond to pressed multilayered powders. $f$ I Field-dependent magnetoresistance (MR) of $\mathrm{Mo}_{2} \mathrm{TiC}_{2}$ and $\mathrm{Ti}_{3} \mathrm{C}_{2}$ taken at $10 \mathrm{~K}$. MR $(\%)=\left(R_{\mathrm{H}}-R_{0}\right) \times 100 / R_{0}$, where $R_{\mathrm{H}}$ indicates resistance under a magnetic field and $R_{0}$ refers to the resistance in the absence of an applied magnetic field. Panels a-f were adapted with permission from Ref. ${ }^{56}$, Royal Society of Chemistry. 
Ferromagnetic and antiferromagnetic properties have been predicted for some termination-free MXenes, although magnetism disappears in presence of surface terminations ${ }^{18,27,108,131}$. Of all MXenes, two $-\mathrm{Cr}_{2} \mathrm{CT}_{x}$ and $\mathrm{Cr}_{2} \mathrm{NT}_{x}$ - have been predicted to possess a magnetic moment, even with surface terminations ${ }^{18,108}$; however, their magnetic nature is not clear yet. In one study, terminated Cr-MXenes were predicted to be ferromagnetic ${ }^{18}$; by contrast, when antiferromagnetic configuration was considered, terminated $\mathrm{Cr}_{2} \mathrm{CT}_{x}$ and $\mathrm{Cr}_{2} \mathrm{NT}_{x}$ were determined as antiferromagnetic ${ }^{108,132}$, except $\mathrm{Cr}_{2} \mathrm{NO}_{2}$, which remained ferromagnetic ${ }^{132}$. These Cr-MXenes are yet to be produced experimentally. In 2015, the first chromium-containing MXene, $\mathrm{Cr}_{2} \mathrm{TiC}_{2} \mathrm{~T}_{x}^{20}$, was synthesized; however, the magnetic properties of this MXene are yet to be characterized.

\section{Energy storage applications of $2 D$ carbides} MXenes in batteries

MXenes have wide chemical and structural variety. For this reason, theoretical studies can help to define the most promising candidates for energy-storage applications. For example, it was found that in terms of theoretical gravimetric capacity (that is, the amount of energy that can be stored per gram of material), MXenes with low formula weights, such as $\mathrm{Ti}_{2} \mathrm{C}, \mathrm{Nb}_{2} \mathrm{C}, \mathrm{V}_{2} \mathrm{C}$ and $\mathrm{Sc}_{2} \mathrm{C}$, are the most promising ${ }^{81}$. Therefore, $\mathrm{M}_{2} \mathrm{X}$ electrodes are expected to show higher gravimetric capacities than their $\mathrm{M}_{3} \mathrm{X}_{2}$ and $\mathrm{M}_{4} \mathrm{X}_{3}$ counterparts. Because the bonds between $\mathrm{M}$ and $\mathrm{X}$ are too strong to be broken easily, it is reasonable to assume that ions penetrate only between the MXene sheets. This is supported by all available experimental data. For example, by comparing $\mathrm{Ti}_{2} \mathrm{C}$ and $\mathrm{Ti}_{3} \mathrm{C}_{2}$, both of which have the same surface chemistry but the latter has one inactive $\mathrm{TiC}$ layer, $\mathrm{Ti}_{2} \mathrm{C}$ should have $\sim 50 \%$ higher gravimetric capacitance than $\mathrm{Ti}_{3} \mathrm{C}_{2}$. This was confirmed experimentally: the gravimetric capacity of $\mathrm{Ti}_{2} \mathrm{CT}_{x}$ for $\mathrm{Li}^{+}$uptake is $\sim 1.5$ times higher than that of $\mathrm{Ti}_{3} \mathrm{C}_{2} \mathrm{~T}_{x}$ prepared in the same way ${ }^{63,135}$.

It is important to note that the capacity is not completely defined by the formula weight. For example, $\mathrm{V}_{2} \mathrm{CT}_{x}$ shows the highest $\mathrm{Li}^{+}$capacity of all MXenes tested under similar conditions $\left(280 \mathrm{mAhg}^{-1}\right.$ at a $1 \mathrm{C}$ and $125 \mathrm{mAh} \mathrm{g}^{-1}$ at $10 \mathrm{C}$ cycling rates) ${ }^{17}$. Moreover, although $\mathrm{Nb}$ atoms are heavier than $\mathrm{Ti}$, the gravimetric capacity of $\mathrm{Nb}_{2} \mathrm{CT}_{x}$ is higher than that for $\mathrm{Ti}_{2} \mathrm{CT}_{x}$ at the same cycling rate $\left(180 \mathrm{mAhg}^{-1} \text { for } \mathrm{Nb}_{2} \mathrm{CT}_{x} \text { versus } 110 \mathrm{mAh} \mathrm{g}^{-1} \text { of } \mathrm{Ti}_{2} \mathrm{CT}_{x} \text { at } 1 \mathrm{C}\right)^{17}$. In part, this can be explained by the complex nature of ion storage. The surface terminations are one particular factor than can affect the performance, as demonstrated by theoretical investigation ${ }^{71,81,136}$. For example, oxygen terminations deemed most favourable, whereas hydroxyls and fluorines result in lower capacity as well as impeded Li-ion transport ${ }^{71,76}$.

The key features of ion intercalation into MXenes from organic electrolytes have been revealed theoretically and confirmed experimentally (FIG. 6a). When the mechanism of Li-ion charge storage in $\mathrm{Ti}_{3} \mathrm{C}_{2} \mathrm{~T}_{x}$ was studied using in-situ X-ray absorption spectroscopy (XAS), it was shown that there is a continuous change in the transition metal (that is, Ti) oxidation state during charge and discharge (regions I and IV in FIG. $6 \mathrm{~b}$ ) up to $0.5 \mathrm{~V}$ vs. $\mathrm{Li} / \mathrm{Li}^{+71}$. Interestingly, further decrease in potential (regions II and III in FIG. 6b) does not translate into a change in oxidation state. Instead, thanks to the 2D nature and conductivity of MXenes, lithium atoms can reversibly form an additional layer (as shown in FIG. 6a). This provides a two-fold boost of the capacity and this mechanism is also expected to be applicable to other MXenes ${ }^{136,137}$. Further increase in capacity was achieved by optimization of the electrode architecture, hybridizing porous MXene flakes with carbon nanotubes, resulting in a Li-ion capacity in excess of 750 mAh $\mathrm{g}^{-1} 138$.

MXenes can accommodate ions of various sizes between 2D layers of $\mathrm{M}_{n+1} \mathrm{X}_{n} \mathrm{~T}_{x}$. This makes them suitable for non-lithium-ion batteries (NLiBs), for which the current selection of electrode materials is limited. Theoretical capacities for some oxygen-terminated MXenes in Na-, 
$\mathrm{K}-, \mathrm{Mg}-, \mathrm{Ca}-$ and Al-ion batteries are shown in FIG. $6 \mathrm{c}^{136}$. Note that the formation of an additional metal layer was predicted for $\mathrm{Na}^{+}$and other ions, which would result in a doubling of the capacity. Moreover, thanks to chemical and structural variability and surface chemistry tunability, different MXenes can provide a range of working potentials, which makes some of them suitable as anodes ${ }^{139}$ and some of them suitable as cathodes ${ }^{140}$ (FIG. 6d).

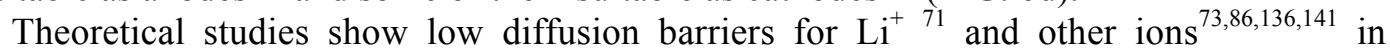
MXenes. This is in agreement with the remarkably high-rate performance experimentally observed for several MXenes ${ }^{17,63,139}$. Typical capacities of MXene-based electrodes at rates beyond $10 \mathrm{C}$ (that is, a 6-minute charging time) fall in the range of $50-200 \mathrm{mAh} \mathrm{g}^{-1}$. As a result, the MXenes in metal-ion batteries do not display a plateau region in the galvanostatic chargedischarge profiles (FIG. 6b), which resembles the behaviour of supercapacitors.

MXene-based composite electrodes hold particular promise for high-performance, highrate batteries. For example, $\mathrm{Ti}_{2} \mathrm{CT}_{x}$ or $\mathrm{Ti}_{3} \mathrm{C}_{2} \mathrm{~T}_{x}$ were used as conductive sulfur hosts in a $\mathrm{Li}-\mathrm{S}$ batteries, resulting in dramatically improved cyclability and stability owing to the strong interaction of polysulfide species with MXene functional groups ${ }^{142,143}$ (FIG. 6e). Similarly, encapsulation of $\mathrm{Sn}$ nanoparticles between layers of $\mathrm{Ti}_{3} \mathrm{C}_{2} \mathrm{~T}_{x}$ results in stable performance with a superior volumetric capacity approaching $2000 \mathrm{mAh} \mathrm{g}^{-1}{ }^{144}$. A similar approach of co-integration (hybridization) with MXenes can be applied to substantially improve the cycle life and rate capability of other high-capacity electrode materials that experience a significant volume change upon intercalation. In this approach, MXenes provide a conductive matrix that accommodates expansion and contraction of particles while maintaining structural and electrical connectivity.

a

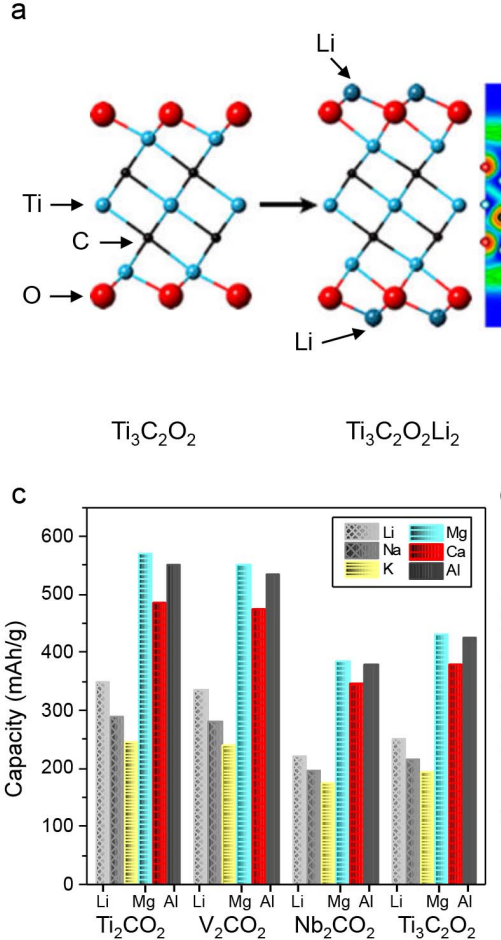

- $\bullet$
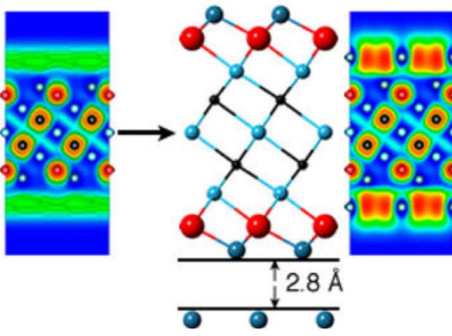

$\mathrm{Ti}_{3} \mathrm{C}_{2} \mathrm{O}_{2} \mathrm{Li}_{2} \mathrm{Li}_{2}$

d

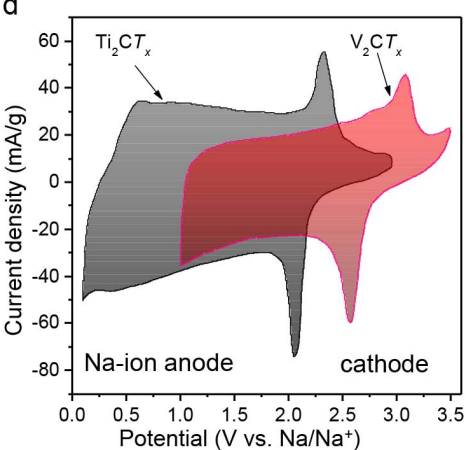

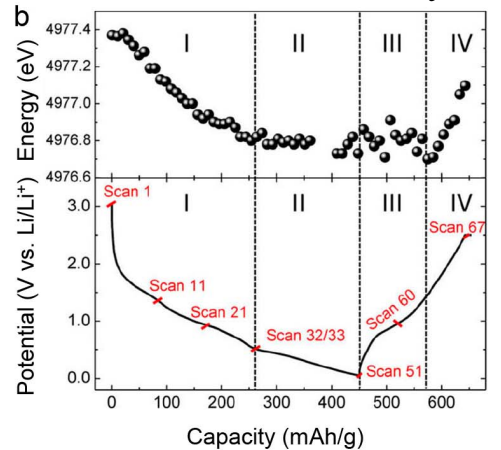

e

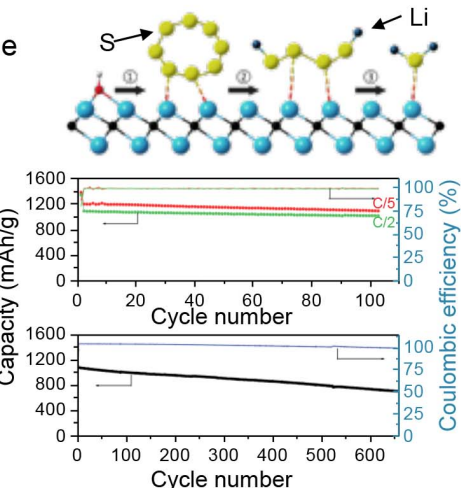

Figure $6 \mathrm{I}$ MXenes as electrodes in different kinds of batteries. al Schematic illustration of the $\mathrm{Ti}_{3} \mathrm{C}_{2} \mathrm{~T}_{x}$ lithiation process. The valence electron localization functions are shown with and without the addition lithium layer. bl Variation of Ti edge energy (at half height of normalized XANES spectra) vs capacity during lithiation and delithiation combined with the corresponding voltage profiles. cl Lithium and none-lithium ions theoretical capacities on O-terminated MXene nanosheets ${ }^{136}$. dl Cyclic voltammetry profiles of $\mathrm{Ti}_{2} \mathrm{C}^{139}$ and $\mathrm{V}_{2} \mathrm{C}^{140}$ in Na-ion electrolyte. el Performance of $\mathrm{Ti}_{2} \mathrm{C} /$ sulfur composite in Li-S batteries. Top panel: Schematic illustration of replacement of the $\mathrm{Ti}-\mathrm{OH}$ bond on the MXene surface with a S-Ti-C bond on heat treatment or by contact with polysulfides; middle panel: cycling performance of $70 \mathrm{wt} . \% \mathrm{~S} / \mathrm{d}-$ $\mathrm{Ti}_{2} \mathrm{C}$ composite at $\mathrm{C} / 5$ and $\mathrm{C} / 2$; lower panel: long-term cycling at $\mathrm{C} / 2$. Panels a,b adapted with permission from Ref. ${ }^{71}$, American Chemical Society. Panel c adapted with permission from Ref. ${ }^{136}$, American Chemical Society. Panel e adapted with permission from Ref. ${ }^{142}$, Wiley- $\mathrm{VCH}$. 


\section{MXene-based electrochemical capacitors}

MXenes can be spontaneously intercalated by polar organic molecules ${ }^{63-65}$ and metal ions ${ }^{63,145}$. For example, a variety of mono- and multivalent cations (such as $\mathrm{Li}^{+}, \mathrm{Na}^{+}, \mathrm{K}^{+}, \mathrm{NH}_{4}^{+}$ and $\mathrm{Mg}^{2+}$ ) can intercalate MXenes (chemically or electrochemically), occupying electrochemically active cites on the MXene surfaces, and participate in energy storage (FIG. $7 a)^{145-147}$.

$\mathrm{Ti}_{3} \mathrm{C}_{2} \mathrm{~T}_{x}$ is the most studied MXene for electrochemical capacitors. The volumetric capacitance of free-standing $\mathrm{Ti}_{3} \mathrm{C}_{2} \mathrm{~T}_{\mathrm{x}}$ 'paper' electrodes in neutral and basic electrolytes has been demonstrated to be $300-400 \mathrm{~F} \mathrm{~cm}^{-3}$; these outstanding values exceed the best all-carbon electrical double layer capacitors (EDLCs) ) $^{35,145}$ and are comparable to recently reported activated graphenebased electrodes $\left(350 \mathrm{~F} \mathrm{~cm}^{-3}\right){ }^{148}$. Although the shape of the cyclic voltammetry curves slightly differs depending on the cation ${ }^{145,146}$ (FIG. 7b), there are no pronounced peaks and the cyclic voltammetry profiles look 'capacitor-like'. Volumetric capacitance exceeding $900 \mathrm{~F} \mathrm{~cm}^{-3}$ was obtained in $1 \mathrm{M} \mathrm{H}_{2} \mathrm{SO}_{4}$ for a rolled pure $\mathrm{Ti}_{3} \mathrm{C}_{2} \mathrm{~T}_{x}$ clay electrode, presumably because protons are the smallest cations and can thus access the largest number of the electrochemically active sites, especially when $\mathrm{Li}^{+}$ions with water molecules intercalated during the synthesis prevent restacking of MXene sheets. In addition, as can be seen in FIG. 7c, perfect capacitive behaviour is observed for $\mathrm{Ti}_{3} \mathrm{C}_{2} \mathrm{~T}_{x}$ even at fairly high charge and discharge rates ${ }^{35}$. This is in contrast to the slow intercalation of ions usually observed in other layered materials used in battery applications, such as graphite. Interdigitated thin MXene electrodes on flexible substrates demonstrate even better rate performance ${ }^{97,149}$. MXenes also exhibit excellent cyclability, with no change in capacitance reported after 10,000 cycles for $\mathrm{Ti}_{3} \mathrm{C}_{2} \mathrm{~T}_{x}$ electrodes (FIG. $\left.7 \mathrm{f}\right)^{35}$.

The mechanism of high volumetric capacitance of MXene was not immediately clear. Cyclic voltammetry profiles of MXenes have no pronounced redox peaks and resemble those of carbon-based double layer capacitors. However, the accessible specific surface area is not sufficient to explain the performance $\mathrm{e}^{35,145}$. To check whether the mechanism of charge storage is pseudocapacitive (that is, it involves changes in the oxidations state of the transition metal), electrochemical in-situ electrochemical XAS measurement was carried out for $\mathrm{Ti}_{3} \mathrm{C}_{2} \mathrm{~T}_{x}(\mathrm{HCl}-\mathrm{LiF}$ etched) in $1 \mathrm{M} \mathrm{H}_{2} \mathrm{SO}_{4}{ }^{150}$. Similar to the case for Li-ion batteries described earlier ${ }^{71}$, changes in the Ti oxidation state were detected through XAS during cycling, which were consistent with the experimental values of the material's capacitance. Therefore, it can be concluded that the mechanism of electrochemical storage of $\mathrm{Ti}_{3} \mathrm{C}_{2} \mathrm{~T}_{x}$ MXene in sulfuric acid is predominantly pseudocapacitive and not diffusion limited, at least up to scan rates of $20 \mathrm{mV} \mathrm{s}^{-135}$.

There are several important factors that affect the volumetric capacitance of MXenes. First, the density of the electrode serves as a conversion factor of gravimetric to volumetric performance. Because carbides are much denser than carbon, freestanding additive-free MXene electrodes typically possess densities from 3-4 $\mathrm{g} \mathrm{cm}^{-3}$, whereas MXene-based composite electrodes with polymer binders and conductive additives have lower densities ranging from 1 to $2.5 \mathrm{~g} \mathrm{~cm}^{-13}$.

Another important factor that affects the gravimetric and consequently volumetric capacitance is the MXene surface chemistry. For example, fluorine-containing functional groups with oxygen-containing groups results in a substantial increase in capacitance. When HFproduced $\mathrm{Ti}_{3} \mathrm{C}_{2} \mathrm{~T}_{x}$ was chemically modified using $\mathrm{KOH}^{151}, \mathrm{~N}_{2} \mathrm{H}_{4}{ }^{95}$, or DMSO ${ }^{136,145}$ solutions, the gravimetric capacitance values improved by a factor of two to seven, depending on the electrolyte being used, with the most dramatic improvements demonstrated in acidic electrolytes. Interestingly, it was also shown that $\mathrm{Ti}_{3} \mathrm{C}_{2} \mathrm{~T}_{x}$ produced using a $\mathrm{HCl}-\mathrm{LiF}$ mixture (instead of $\mathrm{HF}$ ) possesses predominantly oxygen-containing functionalities ${ }^{94}$. Owing to these functionalities, outstanding volumetric capacitances up to $900 \mathrm{~F} \mathrm{~cm}^{-3}$ were demonstrated. The scalability of the process is notable: electrodes of thicknesses up to $75 \mu \mathrm{m}$ were readily produced by rolling the asreceived $\mathrm{Ti}_{3} \mathrm{C}_{2} \mathrm{~T}_{x}$ (HCl-LiF etched) clay sample and showed capacitance of $350 \mathrm{~F} \mathrm{~cm}^{-3}$ (see FIG. 
$7 \mathrm{~g})^{35}$. It is important to mention that MXenes other than $\mathrm{Ti}_{3} \mathrm{C}_{2} \mathrm{~T}_{x}$ also demonstrate much promise for supercapacitors. For example, $\mathrm{Mo}_{2} \mathrm{CT}_{x}^{40}$ and $\mathrm{Mo}_{2} \mathrm{TiC}_{2} \mathrm{~T}_{x}^{20}$ showed high volumetric capacitance with rectangular cyclic voltammetry profiles.

MXene-based hybrid materials can provide enhanced electrochemical and mechanical performance. For example, it was found that integration of 5-10 wt.\% carbon nanotubes (FIG. 7e), graphene or onion-like carbon results in improved rate performance thanks to better ion accessibility in aqueous ${ }^{121}$ and organic electrolytes ${ }^{64}$ (FIG. $7 \mathrm{~g}$ ). Composites with polymers represent a very important and promising direction for the development of electrode architectures. It was found that polymers with polar functional groups in their chains, such as PVA and PDDA (poly(diallyldimethylammonium chloride)), can intercalate between $\mathrm{Ti}_{3} \mathrm{C}_{2} \mathrm{~T}_{x}$ MXene layers, preventing them from restacking and substantially improving the mechanical properties of the MXene 'papers' without compromising their electrochemical perfromance ${ }^{117}$. If redox-active polymers are used instead of electrochemically inert polymers, enhanced electrochemical performance can be achieved. For example, a 13- $\mu$ m-thick $\mathrm{Ti}_{3} \mathrm{C}_{2} \mathrm{~T}_{x}$-polypyrrole composite demonstrated almost doubled gravimetric capacitance ${ }^{118}$ in comparison with pure $\mathrm{Ti}_{3} \mathrm{C}_{2} \mathrm{~T}_{x}^{35}$ films (420 vs. $240 \mathrm{~F} \mathrm{~g}^{-1}$ at $2 \mathrm{mV} \mathrm{s}^{-1}$ ), whereas the increase in its volumetric capacitance to $\sim 1000$ $\mathrm{F} \mathrm{cm}^{-3}$ compare to pure $\mathrm{Ti}_{3} \mathrm{C}_{2} \mathrm{~T}_{x}^{35}$ films was less dramatic because of the lower density of the composite $\left(2.4\right.$ vs. $\left.3.8 \mathrm{~g} \mathrm{~cm}^{-3}\right)$.
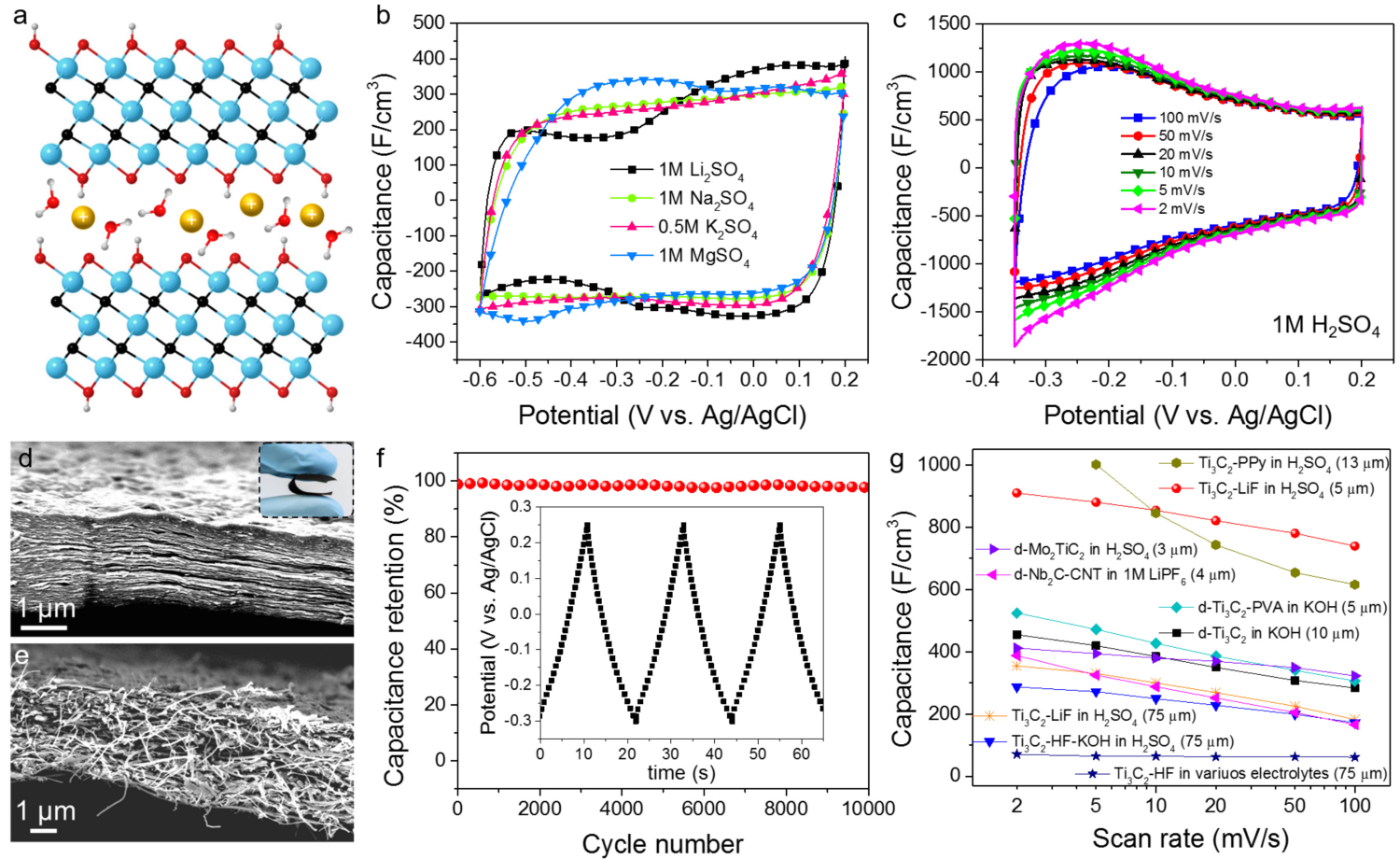

Figure 7I Capacitive performance of MXenes. al Schematic illustration of cation intercalation between $\mathrm{Ti}_{3} \mathrm{C}_{2} \mathrm{~T}_{x}$ layers. The interlayer spacing increases after intercalation. bl Cyclic voltammograms at $2 \mathrm{mV} \mathrm{s}{ }^{-1}$ for a $25-\mu \mathrm{m}$-thick d- $\mathrm{Ti}_{3} \mathrm{C}_{2} \mathrm{~T}_{\mathrm{x}}$ paper electrodes in sulfate electrolytes. cl Cyclic voltammograms at different scan rates for a 5- $\mu \mathrm{m}$-thick rolled, freestanding $\mathrm{Ti}_{3} \mathrm{C}_{2} \mathrm{~T}_{x}$ clay electrode in $1 \mathrm{M} \mathrm{H}_{2} \mathrm{SO}_{4}$. d, el Cross-sectional SEM images of $\mathrm{Nb}_{2} \mathrm{CT}_{x}$ (d) and $\mathrm{Nb}_{2} \mathrm{CT}_{x} / \mathrm{CNT}$ composite paper (e). fl Capacitance retention test of a 5- $\mu$ m-thick rolled $\mathrm{Ti}_{3} \mathrm{C}_{2} \mathrm{~T}_{x}$ clay electrode in $1 \mathrm{M} \mathrm{H}_{2} \mathrm{SO}_{4}$. The inset shows galvanostatic cycling data collected at $10 \mathrm{~A} \mathrm{~g}^{-1}$. gl Comparison of rate performances of MXene electrodes. From top to bottom: 13- $\mu \mathrm{m} \mathrm{Ti}{ }_{3} \mathrm{C}_{2} \mathrm{~T}_{x}$ /polypyrrole composite tested in $1 \mathrm{M} \mathrm{H}_{2} \mathrm{SO}_{4}$ (dark gold hexagons) ${ }^{118}$, 5- $\mu \mathrm{m} \mathrm{Ti}{ }_{3} \mathrm{C}_{2} \mathrm{~T}_{x}(\mathrm{LiF})$ clay (red spheres) ${ }^{35}, 5-\mu \mathrm{m} \mathrm{d}-\mathrm{Ti}_{3} \mathrm{C}_{2} \mathrm{~T}_{x} / \mathrm{PVA}$ composite tested in $1 \mathrm{M} \mathrm{KOH}$ (aqua diamonds) ${ }^{117}, 10 \mu \mathrm{m} \mathrm{d}-\mathrm{Ti}_{3} \mathrm{C}_{2} \mathrm{~T}_{x}$ paper electrode in $1 \mathrm{M} \mathrm{KOH}$ (black squares) ${ }^{145}, 3 \mu \mathrm{m} \mathrm{d}-\mathrm{Mo}_{2} \mathrm{CT}_{\mathrm{x}}$ in $1 \mathrm{M} \mathrm{H}_{2} \mathrm{SO}_{4}$ (violet triangles) ${ }^{40}, 4 \mu \mathrm{m} \mathrm{d}-\mathrm{Nb}_{2} \mathrm{C} / \mathrm{CNT}$ composite in $1 \mathrm{M} \mathrm{LiPF}_{6}$ (pink triangles) ${ }^{64}, 75 \mu \mathrm{m} \mathrm{Ti}{ }_{3} \mathrm{C}_{2} \mathrm{~T}_{\mathrm{x}}$ ( $\mathrm{LiF}$ ) rolled clay electrode in $1 \mathrm{M} \mathrm{H}_{2} \mathrm{SO}_{4}$ (orange stars) ${ }^{35}, 75 \mu \mathrm{m} \mathrm{Ti}{ }_{3} \mathrm{C}_{2} \mathrm{~T}_{\mathrm{x}}(\mathrm{HF})-\mathrm{KOH}$ treated in $1 \mathrm{M} \mathrm{H}_{2} \mathrm{SO}_{4}$ (blue triangles) ${ }^{151}, 75 \mu \mathrm{m} \mathrm{Ti}_{3} \mathrm{C}_{2} \mathrm{~T}_{\mathrm{x}}(\mathrm{HF})$ averaged performance in various aqueous electrolytes (dark blue stars $)^{145}$. SEM, scanning electron micscrope. Panel $\mathbf{b}$ adapted with permission from Ref. ${ }^{146}$, Elsevier. Panels $\mathbf{c}$ and $\mathbf{f}$ reproduced with permission from Ref. ${ }^{35}$, Nature Publishing Group. Panels $\mathbf{d}$ and e reproduced with permission from Ref. ${ }^{64}$, Wiley-VCH. 
Another important fact to keep in mind is that MXenes demonstrate excellent performance when cathodic (negative) potentials are applied; yet when the material is subjected to a positive potential in aqueous electrolyte (more than $\sim 0.2-0.4 \mathrm{~V}$ above the open circuit potential, depending on the MXene composition) irreversible oxidation may $\operatorname{start}^{145}$, leading to an increase in resistance and a loss in capacitance. Therefore, asymmetrical cell design with another electrochemically stable material of high capacitance (for example, nitrogen-doped graphene in acidic electrolyte or manganese dioxide in basic or neutral electrolyte) should be implemented as the positive electrode for building durable MXene-based energy-storage devices.

As an alternative to the aqueous systems mentioned above, organic electrolytes can be used. The extended voltage window of organic electrolytes results in a larger energy density $(E=$ $0.5 \mathrm{CV}^{2}$, where $E$ is energy density, $C$ is the capacitance and $V$ is the voltage window) for a given specific capacitances when compared with aqueous electrolytes. However, it is important to remember that the behaviour in aqueous electrolytes cannot be directly translated to performance in organic electrolytes. Thus, it is more appropriate to use the performance of different MXenes in Li-ion batteries as a guideline, because similar electrolytes are used in Li-ion capacitors (the difference is that the counter electrode is activated carbon in this case). Also, because organic electrolytes have a lower conductivity and can feature large organic ions like the tetrabutylammonium cation, the introduction of conductive spacers, such as CNTs, is important for improving the accessibility to ions and, therefore, the capacitive and rate performance. For example, $\mathrm{Nb}_{2} \mathrm{CT}_{x} / \mathrm{CNT}$ paper (FIG. 7e) electrodes showed a high volumetric capacitance of 325 $\mathrm{F} \mathrm{cm}^{-3}$ when tested in a Li-ion capacitor configuration ${ }^{64}$ and $\mathrm{a} \mathrm{Ti}_{3} \mathrm{C}_{2} \mathrm{~T}_{x} / \mathrm{CNT}$ sample demonstrated a capacitance of $245 \mathrm{~F} \mathrm{~cm}^{-3}$ in organic electrolyte ${ }^{123}$. Moreover, promising performance of MXenes in an ionic liquid gel electrolyte within a $3 \mathrm{~V}$ window has recently been demonstrated ${ }^{152}$.

The mechanical response of MXenes can be tuned by cation selection, as shown by insitu AFM experiments ${ }^{146}$. This study also showed that deformations are highly dependent on the cation nature, in particular, the charge-to-size ratio; specifically, highly charged small cations do not change the interlayer spacing of $2 \mathrm{D} \mathrm{Ti}_{3} \mathrm{C}_{2} \mathrm{~T}_{x}$ electrodes, whereas larger cations, with smaller charges, expand the interlayer spaces. This potentially provides a route to creating energy-storage devices with $0 \mathrm{D}$ change upon charging and discharging, which is a key criteria for achieving a long lifetime and minimizing energy dissipation.

\section{Applications other than energy storage}

Rich chemistry and a variety of MXene structures make them promising candidates for many applications. Energy storage has been the first and most studied application of MXenes. However, there are potentially other applications in which MXenes can outperform other materials. For example, flexible films of $\mathrm{Ti}_{3} \mathrm{C}_{2} \mathrm{~T}_{\mathrm{x}}$ showed the highest electromagnetic interference shielding ever reported for a synthetic material of comparable thickness, higher than that of graphene and other carbons ${ }^{68}$. Other applications have also been studied such as reinforcement for composites ${ }^{117}$, water purification ${ }^{153}$, catalysts in the chemical industry ${ }^{154}$, bio- and gassensors $^{85,155}$, lubricants ${ }^{156}$, photocatalysts $^{98}$, electrocatalysts ${ }^{57}$, photothermal therapy ${ }^{157}$, as shown in Table 1 . 
Table 1/ Applications of MXenes beyond energy storage

\begin{tabular}{|c|c|c|c|}
\hline Application & Material & Description & Ref \\
\hline $\begin{array}{l}\text { Structural } \\
\text { composite }\end{array}$ & $\begin{array}{l}\mathrm{Ti}_{3} \mathrm{C}_{2} \mathrm{~T}_{\mathrm{x}}-\text { polyethylene } \\
\mathrm{Ti}_{3} \mathrm{C}_{2} \mathrm{~T}_{\mathrm{x}} \text {-PVA } \\
\mathrm{Ti}_{3} \mathrm{C}_{2} \mathrm{~T}_{\mathrm{x}} \text {-PDDA }\end{array}$ & Structural, improved strengths, hardness, creep, anti-friction & 117,119 \\
\hline $\begin{array}{l}\text { Electromagnetic } \\
\text { interference (EMI) } \\
\text { shielding }\end{array}$ & $\begin{array}{l}\mathrm{Ti}_{3} \mathrm{C}_{2} \mathrm{~T}_{x}, \mathrm{Mo}_{2} \mathrm{TiC}_{2} \mathrm{~T}_{x} \\
\mathrm{Mo}_{2} \mathrm{Ti}_{2} \mathrm{C}_{3} \mathrm{~T}_{x} \\
\mathrm{Ti}_{3} \mathrm{C}_{2} \mathrm{~T}_{x} \text {-Sodium } \\
\text { alginate }\end{array}$ & $\begin{array}{l}\text { MXene paper and its composite thin filtered papers block as good } \\
\text { as aluminium and copper, from low frequencies ( } 30 \mathrm{MHz} \text { to } 1.5 \\
\mathrm{GHz} \text { ) to X-band ( } 8.2 \text { to } 12.4 \mathrm{GHz})\end{array}$ & $68,159,160$ \\
\hline \multirow{4}{*}{ Water purification } & $\mathrm{Ti}_{3} \mathrm{C}_{2}(\mathrm{OH} / \mathrm{ONa})_{x} \mathrm{~F}_{2-x}$ & Lead sorption & 153 \\
\hline & $\mathrm{TiO}_{2}-\mathrm{C} / \mathrm{TiC}$ & Toxic heavy metal $\mathrm{Cr}(\mathrm{VI})$ adsorption & 161 \\
\hline & $\mathrm{Ti}_{3} \mathrm{C}_{2}(\mathrm{OH})_{2}$ & Heavy metal adsorption (for example, lead) & 162 \\
\hline & $\mathrm{Ti}_{3} \mathrm{C}_{2} \mathrm{~T}_{x}$-Iron oxide & Phosphate sequestration & 163 \\
\hline Water desalination & $\mathrm{Ti}_{3} \mathrm{C}_{2} \mathrm{~T}_{x}$ & $\begin{array}{l}\text { Freestanding membranes for the charge- and size-selective } \\
\text { rejection of ions and molecules }\end{array}$ & 82,164 \\
\hline Nanofiltration & $\begin{array}{l}\mathrm{Ti}_{3} \mathrm{C}_{2} \mathrm{~T}_{\mathrm{x}}-\mathrm{PEI} \text { and } \\
\text { PDMS }\end{array}$ & Solvent resistant nanofiltration for alcohol-based system & 120 \\
\hline Dye adsorption & $\mathrm{Ti}_{3} \mathrm{C}_{2} \mathrm{~T}_{\mathrm{x}}$ & Multilayered MXene powder to adsorb methylene blue & 98 \\
\hline \multirow{2}{*}{$\begin{array}{l}\text { Nuclear waste } \\
\text { management }\end{array}$} & $\mathrm{Ti}_{3} \mathrm{C}_{2}(\mathrm{OH})_{2}$ & Uranyl species adsorption & 165 \\
\hline & $\mathrm{V}_{2} \mathrm{CT}_{x}$ & Uranium $(\mathrm{U}(\mathrm{VI}))$ sorbent & 166 \\
\hline $\mathrm{CO}_{2}$ sensor & $\mathrm{V}_{2} \mathrm{C}-\mathrm{PDMAEMA}$ & Smart $\mathrm{CO}_{2}$ and temperature sensors & 158 \\
\hline $\mathrm{NH}_{3}$ sensor & $\mathrm{Ti}_{2} \mathrm{CO}_{2}$ & $\mathrm{NH}_{3}$ sensor or capturer with high sensitivity and selectivity & 85,167 \\
\hline CO catalyst & Ti-anchored $\mathrm{Ti}_{2} \mathrm{CO}_{2}$ & First-principles computations on CO catalytic oxidation & 168 \\
\hline $\begin{array}{l}\mathrm{O}_{2} \text { evolution } \\
\text { electrocatalyst }\end{array}$ & $\mathrm{Ti}_{3} \mathrm{C}_{2} \mathrm{~T}_{x}-$ graphitic $\mathrm{C}_{3} \mathrm{~N}_{4}$ & $\begin{array}{l}\text { Freestanding, binder-free flexible oxygen electrode with high } \\
\text { activity and strong durability for rechargeable } \mathrm{Zn} \text {-air batteries }\end{array}$ & 169 \\
\hline $\mathrm{H}_{2}$ generation & $\mathrm{RuNi}-\mathrm{Ti}_{3} \mathrm{C}_{2} \mathrm{~T}_{x}$ & Hydrogen generation from hydrolysis of ammonia borane & 170 \\
\hline $\begin{array}{l}\text { Ammonium } \\
\text { perchlorate } \\
\text { decomposition }\end{array}$ & $\mathrm{Ti}_{3} \mathrm{C}_{2} \mathrm{~T}_{\mathrm{x}}-\mathrm{Cu}_{2} \mathrm{O}$ & $\begin{array}{l}\text { Thermal decomposition of ammonium perchlorate for rocket } \\
\text { propellant combustion efficiency }\end{array}$ & 171 \\
\hline Photocatalysis & $\mathrm{Ti}_{3} \mathrm{C}_{2} \mathrm{~T}_{x}-\mathrm{TiO}_{2}$ & Organic contaminants decomposition, water purification & 172 \\
\hline $\begin{array}{l}\mathrm{N}_{2} \text { capture and } \mathrm{NH}_{3} \\
\text { production }\end{array}$ & $\begin{array}{l}\mathrm{Ti}_{3} \mathrm{C}_{2} \mathrm{~T}_{x}, \mathrm{~V}_{3} \mathrm{C}_{2} \mathrm{~T}_{x} \\
\mathrm{Nb}_{3} \mathrm{C}_{2} \mathrm{~T}_{x}\end{array}$ & Capturing $\mathrm{N}_{2}$ and catalytic conversion to $\mathrm{NH}_{3}$ & 173 \\
\hline Bio-sensors & $\mathrm{Ti}_{3} \mathrm{C}_{2} \mathrm{~T}_{x}$ & $\begin{array}{l}\text { Neural activity probe, dopamine label-free detection, monitoring } \\
\text { spiking activity in hippocampal neuron, enzyme immobilization }\end{array}$ & 155,174 \\
\hline $\begin{array}{l}\text { Antibacterial } \\
\text { activity }\end{array}$ & $\mathrm{Ti}_{3} \mathrm{C}_{2} \mathrm{~T}_{x}$ & $\begin{array}{l}\text { Resistance to biofouling: against Escherichia coli (E. coll) and } \\
\text { Bacillus subtilis (B. subtilis) }\end{array}$ & 175 \\
\hline $\begin{array}{l}\text { Photothermal } \\
\text { therapy }\end{array}$ & $\mathrm{Ti}_{3} \mathrm{C}_{2} \mathrm{~T}_{x}$ & $\begin{array}{l}\text { Laser irradiation for } 5 \text { min increased the } \\
\text { MXene colloid temperature above the photoablation limit of } 60^{\circ} \mathrm{C}\end{array}$ & 157 \\
\hline Cement hydration & $\mathrm{Ti}_{3} \mathrm{C}_{2} \mathrm{~T}_{x}$ & Improving the early-age compressive strength of cement paste & 176 \\
\hline Electronics & MXenes-TMDs & $\begin{array}{l}\text { From field-effect transistors (FET) to semiconductors with tunable } \\
\text { band gaps }\end{array}$ & $61,77,80,106$ \\
\hline Lubrication & $\mathrm{Ti}_{3} \mathrm{C}_{2} \mathrm{~T}_{x}$ & 1 wt.\% $\quad \mathrm{Ti}_{3} \mathrm{C}_{2} \mathrm{~T}_{x} \quad$ as a lubrication additive in base oil & 156,177 \\
\hline
\end{tabular}

\section{Conclusions}

2D carbides, carbonitrides and nitrides were produced in the past 5 years by selective etching and exfoliation of layered ternary precursors forming a large family of 2D materials named MXenes. The synthesis process adds hydroxyl, oxygen and fluorine terminations, leading to hydrophilicity of MXene surfaces. Hydrophilicity and high surface charge (negative zeta potential exceeding $-30 \mathrm{mV}$ ) lead to stable water-based colloidal solutions that do not require surfactants for stabilization. This makes processing of MXenes easy, facilitating applications such as device printing and coating/films manufacturing. As a result, both freestanding films and coatings on various substrates have been produced by a variety of techniques, from spray and spin coating to vacuum assisted filtration. 
Attractive electronic, optical, plasmonic and thermoelectric properties have been predicted for many MXenes. High metallic conductivity has been reported for $\mathrm{Ti}_{3} \mathrm{C}_{2} \mathrm{~T}_{x}$ MXene even in the presence of surface functional groups and with water between the layers. By contrast, $\mathrm{Mo}_{2} \mathrm{CT}_{x}$ and $\mathrm{Mo}_{2} \mathrm{TiC}_{2} \mathrm{~T}_{x}$ show semiconductor-like behaviour. A band gap of about $0.9 \mathrm{eV}$ was calculated for oxygen terminated $\mathrm{Ti}_{2} \mathrm{C}$ and Dirac cones are expected for the fluorine-terminated $\mathrm{Ti}_{2} \mathrm{C}$, but those and many other property predictions are still waiting for experimental verification. In addition to these properties, MXene films and polymer-bonded MXenes show good mechanical properties.

Cations, including multivalent ones, and polar organic molecules intercalate MXenes allowing for control of interlayer spacing, and enabling use of MXenes in energy-storage applications, as well as water desalination and purification. A combination of high electronic conductivity, oxide/hydroxide-like surface with redox-active transition metal atoms exposed make MXenes very attractive for fabrication of electrodes. Their energy-storage applications already cover areas from $\mathrm{Li}$-ion and $\mathrm{Na}$-ion batteries and capacitors, to $\mathrm{Li}-\mathrm{S}$ batteries to supercapacitors. Extremely high values of volumetric capacitance have been reached in sulfuric acid electrolytes, and promising capacitive performance has been demonstrated in aqueous neutral and basic electrolyte, as well as in organic and ionic liquid electrolytes. Moreover, a continuous change in the oxidation state of titanium in $\mathrm{Ti}_{3} \mathrm{C}_{2}$-based electrodes upon charging/discharging has been identified, demonstrating dominant contribution of the pseudocapacitance to charge storage. This not only explains how high capacitance can be demonstarted by a material with a moderate surface area, but also opens new avenues for achieving high energy density storage at high charging rates.

\section{Gaps in the current knowledge}

With the first MXene discovered only in 2011, there are many open questions that need to be addressed before the 2D metallic and semiconducting properties of MXenes can be used to the fullest extent.

Over one hundred distinct compositions that have been predicted when surface terminations and multi-element MXenes are taken into account, and many more layered ternary metal carbides and nitrides are waiting to be transformed to MXenes. Any layered transition metal carbide or nitride separated with A-group metals and their carbides and nitrides can potentially be selectively etched and exfoliated to form MXene. Computational studies have been performed on many MXenes for which ternary carbide precursors have not yet been produced, such as $\mathrm{Sc}_{2} \mathrm{C}, \mathrm{Hf}_{2} \mathrm{C}$ or $\mathrm{W}_{2} \mathrm{C}$. Thus, the synthesis of new MAX phases and other layered carbide and nitride precursors becomes an important research direction.

Predictions of the electrical, thermoelectric, magnetic and other properties for many MXenes that have already been produced or can be made from available precursors should be verified experimentally. In this context, computational studies should further guide the synthesis of MXenes by attracting the attention of experimentalists to the synthesis of the most promising compounds.

Characterization of surface chemistry of various MXenes after synthesis, drying and aging is important, but it is even more important to develop methods for achieving uniform terminations with the same kind of surface moieties (for example, $\mathrm{OH}, \mathrm{F}, \mathrm{O}$ or $\mathrm{H}$ ) for different applications. MXenes with no surface functional groups have yet to be produced. These must be synthesized by physical or chemical vapour deposition methods in vacuum.

In the energy-storage applications of MXenes, minimization of the first cycle irreversibility observed after $\mathrm{Li}$ - and $\mathrm{Na}$-ion intercalation is of great practical importance. Better understanding of intercalation of multivalent (for example, $\mathrm{Al}^{3+}, \mathrm{Mg}^{2+}$ or $\mathrm{Zn}^{2+}$ ) and large organic ions would provide important guidelines for the development of electrode materials for the next generation of batteries and supercapacitors. 
Understanding and control of the ion dynamics between MXene sheets can enable development of high-power supercapacitors and may even allow low-resistance MXene-based devices to replace electrolytic capacitors. Understanding of catalytic and electrocatalytic properties of MXene electrocatalysts will open new avenues in energy conversion. Conversely, suppression of electrocatalytic processes on the surface of MXenes would increase the voltage window and therefore, the amount of energy stored, as well as the cycle life, in battery and supercapacitor applications.

Mechanical characterization of single MXene flakes should be conducted to determine their intrinsic mechanical properties. Structural and multifunctional composites should be enabled by covalently attaching polymer chains to strong and rigid MXene layers.

\section{Acknowledgements}

We worked closely with Profs. Michel W. Barsoum (Drexel University) and Prof. Patrice Simon (Paul Sabatier University) on MXene synthesis and energy storage, respectively. Y.G. is grateful to numerous graduate students and post-docs, as well as collaborators at Drexel and elsewhere, who worked with him on exploration of MXenes. Our research on MXenes was supported by the Fluid Interface Reactions, Structures and Transport (FIRST) Center, an Energy Frontier Research Center funded by the U.S. Department of Energy, Office of Science, and Office of Basic Energy Sciences. B.A. was also supported by King Abdullah University of Science and Technology under the KAUST-Drexel University Competitive Research Grant.

\section{Competing interests}

The authors declare no competing interests. 


\section{References}

1. Nicolosi, V., Chhowalla, M., Kanatzidis, M. G., Strano, M. S. \& Coleman, J. N. Liquid Exfoliation of Layered Materials. Science 340, 1226419 (2013).

2. Fiori, G. et al. Electronics based on two-dimensional materials. Nat. Nanotechnol. 9, 768-779 (2014).

3. Xia, F., Wang, H., Xiao, D., Dubey, M. \& Ramasubramaniam, A. Two-dimensional material nanophotonics. Nat. Photon. 8, 899-907 (2014).

4. Koppens, F. et al. Photodetectors based on graphene, other two-dimensional materials and hybrid systems. Nat. Nanotechnol. 9, 780-793 (2014).

5. Akinwande, D., Petrone, N. \& Hone, J. Two-dimensional flexible nanoelectronics. Nat. Commun. 5, 5678, 5678 (2014).

6. Cepellotti, A. et al. Phonon hydrodynamics in two-dimensional materials. Nat. Commun. 6, 6400, 6400 (2015).

7. Geim, A. \& Grigorieva, I. Van der Waals heterostructures. Nature 499, 419-425 (2013).

8. Lalmi, B. et al. Epitaxial growth of a silicene sheet. Appl. Phys. Lett. 97, 223109 (2010).

9. Cahangirov, S., Topsakal, M., Aktürk, E., Şahin, H. \& Ciraci, S. Two-and one-dimensional honeycomb structures of silicon and germanium. Phys. Rev. Lett. 102, 236804 (2009).

10. Dávila, M., Xian, L., Cahangirov, S., Rubio, A. \& Le Lay, G. Germanene: a novel twodimensional germanium allotrope akin to graphene and silicene. New J. Phys. 16, 095002 (2014).

11. Liu, H. et al. Phosphorene: an unexplored 2D semiconductor with a high hole mobility. ACS Nano 8, 4033-4041 (2014).

12. Li, L. et al. Black phosphorus field-effect transistors. Nat. Nanotechnol. 9, 372-377 (2014).

13. Ataca, C., Sahin, H. \& Ciraci, S. Stable, single-layer $\mathrm{MX}_{2}$ transition-metal oxides and dichalcogenides in a honeycomb-like structure. J. Phys. Chem. C 116, 8983-8999 (2012).

14. Osada, M. \& Sasaki, T. Two - Dimensional Dielectric Nanosheets: Novel Nanoelectronics From Nanocrystal Building Blocks. Adv. Mater. 24, 210-228 (2012).

15. Naguib, M. et al. Two-Dimensional Nanocrystals Produced by Exfoliation of $\mathrm{Ti}_{3} \mathrm{AlC}_{2}$. $A d v$. Mater. 23, 4248-4253 (2011).

This is the report on discovery of $\mathrm{Ti}_{3} \mathrm{C}_{2} \mathrm{~T}_{x}$ MXene.

16. Naguib, M. et al. Two-Dimensional Transition Metal Carbides. ACS Nano 6, 1322-1331 (2012).

This is the report on discovery of different MXenes, creating a family of $2 D$ materials.

17. Naguib, M. et al. New Two-Dimensional Niobium and Vanadium Carbides as Promising Materials for Li-Ion Batteries. J. Am. Chem. Soc. 135, 15966-15969 (2013).

18. Khazaei, M. et al. Novel Electronic and Magnetic Properties of Two-Dimensional Transition Metal Carbides and Nitrides. Adv. Funct. Mater. 23, 2185-2192 (2013).

The first computational study on electronic and magnetic properties of all the $\mathrm{M}_{2} \mathrm{C} M X e n e s$.

19. Ghidiu, M. et al. Synthesis and characterization of two-dimensional $\mathrm{Nb}_{4} \mathrm{C}_{3}$ (MXene). Chem. Commun. 50, 9517-9520 (2014).

20. Anasori, B. et al. Two-Dimensional, Ordered, Double Transition Metals Carbides (MXenes). ACS Nano 9, 9507-9516 (2015). This study expanded the family of MXenes by introducing ordered double transition metal MXenes.

21. Gogotsi, Y. Chemical vapour deposition: Transition metal carbides go 2D. Nat. Mater. 14, 1079-1080 (2015).

22. Naguib, M., Mochalin, V. N., Barsoum, M. W. \& Gogotsi, Y. MXenes: A New Family of Two-Dimensional Materials. Adv. Mater. 26, 992-1004 (2014).

23. Kurtoglu, M., Naguib, M., Gogotsi, Y. \& Barsoum, M. W. First principles study of twodimensional early transition metal carbides. MRS Commun. 2, 133-137 (2012). 
24. Khazaei, M., Arai, M., Sasaki, T., Estili, M. \& Sakka, Y. Two-dimensional molybdenum carbides: potential thermoelectric materials of the MXene family. Phys. Chem. Chem. Phys. 16, 7841-7849 (2014).

25. Urbankowski, P. et al. Synthesis of two-dimensional titanium nitride $\mathrm{Ti}_{4} \mathrm{~N}_{3}$ (MXene). Nanoscale 8, 11385-11391 (2016).

The first experimental report on synthesis of a nitride MXene by etching in molten salts.

26. Ivanovskii, A. L. \& Enyashin, A. N. Graphene-like transition-metal nanocarbides and nanonitrides. Russ. Chem. Rev. 82, 735-746 (2013).

27. Shein, I. R. \& Ivanovskii, A. L. Graphene-like titanium carbides and nitrides $T_{n} i_{n+1} C_{n}, T_{n+1} N_{n}$ $(\mathrm{n}=1,2$, and 3) from de-intercalated MAX phases: First-principles probing of their structural, electronic properties and relative stability. Comput. Mater. Sci. 65, 104-114 (2012).

28. Xie, Y. \& Kent, P. Hybrid density functional study of structural and electronic properties of functionalized $\mathrm{Ti}_{\mathrm{n}+1} \mathrm{X}_{\mathrm{n}}(\mathrm{X}=\mathrm{C}, \mathrm{N})$ monolayers. Phys. Rev. B 87, 235441 (2013).

29. Gao, G. et al. Monolayer MXenes: promising half-metals and spin gapless semiconductors. Nanoscale 8, 8986-8994 (2016).

30. Khazaei, M. et al. Nearly free electron states in MXenes. Phys. Rev. B 93, 205125 (2016).

31. Barsoum, M. W. MAX Phases: Properties of Machinable Ternary Carbides and Nitrides. (John Wiley \& Sons, 2013).

32. Barsoum, M. W. \& Radovic, M. Elastic and Mechanical Properties of the MAX Phases. Annu. Rev. Mater. Res. 41, 195-227 (2011).

33. Eklund, P., Beckers, M., Jansson, U., Högberg, H. \& Hultman, L. The $M_{n+1} A X_{n}$ phases: Materials science and thin-film processing. Thin Solid Films 518, 1851-1878 (2010).

34. Anasori, B. et al. Experimental and theoretical characterization of ordered MAX phases $\mathrm{Mo}_{2} \mathrm{TiAlC}_{2}$ and $\mathrm{Mo}_{2} \mathrm{Ti}_{2} \mathrm{AlC}_{3}$. J. Appl. Phys. 118, 094304 (2015).

35. Ghidiu, M., Lukatskaya, M. R., Zhao, M.-Q., Gogotsi, Y. \& Barsoum, M. W. Conductive two-dimensional titanium carbide 'clay' with high volumetric capacitance. Nature 516, 78-81 (2014).

This study showed a new method for MXene synthesis and demonstrated clay-like behavior of MXene produced by etching in $\mathrm{HCl}-\mathrm{LiF}$ and its high volumetric capacitance.

36. Halim, J. et al. Transparent Conductive Two-Dimensional Titanium Carbide Epitaxial Thin Films. Chem. Mater. 26, 2374-2381 (2014).

37. Karlsson, L. H., Birch, J., Halim, J., Barsoum, M. W. \& Persson, P. O. Atomically resolved structural and chemical investigation of single MXene sheets. Nano Lett. 15, 4955-4960 (2015).

38. Wang, L. et al. Synthesis and electrochemical performance of Ti3C2Tx with hydrothermal process. Electron. Mater. Lett. 12, 702-710 (2016).

39. Meshkian, R. et al. Synthesis of two-dimensional molybdenum carbide, $\mathrm{Mo}_{2} \mathrm{C}$, from the gallium based atomic laminate $\mathrm{Mo}_{2} \mathrm{Ga}_{2}$ C. Scripta Mater. 108, 147-150 (2015).

40. Halim, J. et al. Synthesis and Characterization of 2D Molybdenum Carbide (MXene). Adv. Funct. Mater. 26, 3118-3127 (2016).

41. Zhou, J. et al. A Two - Dimensional Zirconium Carbide by Selective Etching of $\mathrm{Al}_{3} \mathrm{C}_{3}$ from Nanolaminated $\mathrm{Zr}_{3} \mathrm{Al}_{3} \mathrm{C}_{5}$. Angew. Chem. 128, 5092-5097 (2016).

42. Lin, Z., He, L., Li, M., Wang, J. \& Zhou, Y. Layered stacking characteristics of ternary zirconium aluminum carbides. J. Mater. Res. 22, 3058-3066 (2007).

43. Wang, J., Zhou, Y., Liao, T. \& Lin, Z. Trend in crystal structure of layered ternary T-Al-C carbides ( $\mathrm{T}=\mathrm{Sc}, \mathrm{Ti}, \mathrm{V}, \mathrm{Cr}, \mathrm{Zr}, \mathrm{Nb}, \mathrm{Mo}, \mathrm{Hf}, \mathrm{W}$, and Ta). J. Mater. Res. 22, 2685-2690 (2007).

44. Gesing, T. M. \& Jeitschko, W. The Crystal Structures of $\mathrm{Zr}_{3} \mathrm{Al}_{3} \mathrm{C}_{5}, \mathrm{ScAl}_{3} \mathrm{C}_{3}$, and $\mathrm{UAl}_{3} \mathrm{C}_{3}$ and Their Relation to the Structures of $\mathrm{U}_{2} \mathrm{Al}_{3} \mathrm{C}_{4}$ and $\mathrm{Al}_{4} \mathrm{C}_{3}$. J. Solid State Chem. 140, 396-401 (1998). 45. Xie, J. et al. Atomically-thin molybdenum nitride nanosheets with exposed active surface sites for efficient hydrogen evolution. Chem. Sci. 5, 4615-4620 (2014). 
46. Hoffman, E. N., Yushin, G., El-Raghy, T., Gogotsi, Y. \& Barsoum, M. W. Micro and mesoporosity of carbon derived from ternary and binary metal carbides. Microporous Mesoporous Mater. 112, 526-532 (2008).

47. Presser, V., Heon, M. \& Gogotsi, Y. Carbide - Derived Carbons-From Porous Networks to Nanotubes and Graphene. Adv. Funct. Mater. 21, 810-833 (2011).

48. Barsoum, M. et al. The Topotactic Transformation of $\mathrm{Ti}_{3} \mathrm{SiC}_{2}$ into a Partially Ordered Cubic $\mathrm{Ti}\left(\mathrm{C}_{0.67} \mathrm{Si}_{0.06}\right)$ Phase by the Diffusion of Si into Molten Cryolite. J. Electrochem. Soc. 146, 39193923 (1999).

49. El-Raghy, T., Barsoum, M. \& Sika, M. Reaction of Al with $\mathrm{Ti}_{3} \mathrm{SiC}_{2}$ in the $800-1000^{\circ} \mathrm{C}$ temperature range. Mater. Sci. Eng. A 298, 174-178 (2001).

50. Barsoum, M., Golczewski, J., Seifert, H. \& Aldinger, F. Fabrication and electrical and thermal properties of $\mathrm{Ti}_{2} \mathrm{InC}, \mathrm{Hf}_{2} \mathrm{InC}$ and (Ti, Hf) ${ }_{2} \mathrm{InC}$. J. Alloys Compd. 340, 173-179 (2002).

51. Naguib, M. et al. On the Topotactic Transformation of $\mathrm{Ti}_{2} \mathrm{AlC}$ into a Ti-C-O-F Cubic Phase by Heating in Molten Lithium Fluoride in Air. J. Am. Ceram. Soc. 94, 4556-4561 (2011).

52. Gusev, A. \& Rempel, A. in Materials Science of Carbides, Nitrides and Borides (eds Y. Gogotsi \& R. A. Andrievski) 47-64 (Springer, 1999).

53. Xu, C. et al. Large-area high-quality 2D ultrathin $\mathrm{Mo}_{2} \mathrm{C}$ superconducting crystals. Nat. Mater. 14, 1135-1141 (2015).

54. Mashtalir, O., Naguib, M., Dyatkin, B., Gogotsi, Y. \& Barsoum, M. W. Kinetics of aluminum extraction from $\mathrm{Ti}_{3} \mathrm{AlC}_{2}$ in hydrofluoric acid. Mater. Chem. Phys. 139, 147-152 (2013).

55. Cambaz, G. Z., Yushin, G. N., Gogotsi, Y. \& Lutsenko, V. G. Anisotropic etching of SiC whiskers. Nano Lett. 6, 548-551 (2006).

56. Anasori, B. et al. Control of electronic properties of 2D carbides (MXenes) by manipulating their transition metal layers. Nanoscale Horiz. 1, 227-234 (2016).

57. Seh, Z. W. et al. Two-Dimensional Molybdenum Carbide (MXene) as an Efficient Electrocatalyst for Hydrogen Evolution. ACS Energy Lett. 1, 589-594 (2016).

58. Ghidiu, M. et al. Ion-Exchange and Cation Solvation Reactions in $\mathrm{Ti}_{3} \mathrm{C}_{2}$ MXene. Chem. Mater. 28, 3507-3514 (2016).

59. Lipatov, A. et al. Effect of Synthesis on Quality, Electronic Properties and Environmental Stability of Individual Monolayer $\mathrm{Ti}_{3} \mathrm{C}_{2}$ MXene Flakes. Adv. Electron. Mater. DOI:10.1002/aelm.201600255 (2016).

60. Hu, T. et al. Interlayer Coupling in Two-Dimensional Titanium Carbide MXenes. Phys. Chem. Chem. Phys. 18, 20256-20260 (2016).

61. Xu, J., Shim, J., Park, J.-H. \& Lee, S. MXene Electrode for the Integration of $\mathrm{WSe}_{2}$ and $\mathrm{MoS}_{2}$ Field Effect Transistors. Adv. Funct. Mater. 26, 5328-5334 (2016).

62. Lai, S. et al. Surface group modification and carrier transport property of layered transition metal carbides $\left(\mathrm{Ti}_{2} \mathrm{CT}_{\mathrm{x}}, \mathrm{T}\right.$ : $-\mathrm{OH},-\mathrm{F}$ and $\left.-\mathrm{O}\right)$. Nanoscale 7, 19390-19396 (2015).

63. Mashtalir, O. et al. Intercalation and delamination of layered carbides and carbonitrides. Nat. Commun. 4, 1716 (2013).

First report on intercalation of ions and polar organic molecules between MXene layers and delamination of MXenes to make stable colloidal solutions.

64. Mashtalir, O., Lukatskaya, M. R., Zhao, M. Q., Barsoum, M. W. \& Gogotsi, Y. AmineAssisted Delamination of $\mathrm{Nb}_{2} \mathrm{C}$ MXene for Li-Ion Energy Storage Devices. Adv. Mater. 27, 3501-3506 (2015).

65. Naguib, M., Unocic, R. R., Armstrong, B. L. \& Nanda, J. Large-scale delamination of multilayers transition metal carbides and carbonitrides "MXenes". Dalton Trans. 44, 9353-9358 (2015).

66. Osti, N. C. et al. Effect of Metal Ion Intercalation on the Structure of MXene and Water Dynamics on its Internal Surfaces. ACS Appl. Mater. Interfaces 8, 8859-8863 (2016).

67. Sang, X. et al. Atomic Defects in Monolayer Titanium Carbide $\left(\mathrm{Ti}_{3} \mathrm{C}_{2} \mathrm{~T}_{\mathrm{x}}\right)$ MXene. ACS Nano 10, 9193-9200 (2016). 
68. Shahzad, F. et al. Electromagnetic Interference Shielding with 2D Transition Metal Carbides (MXenes) Science 353, 1137-1140 (2016).

69. Xie, X. et al. Porous Heterostructured MXene/Carbon Nanotube Composite Paper with High Volumetric Capacity for Sodium-Based Energy Storage Devices. Nano Energy 26, 513-523 (2016).

70. Shein, I. R. \& Ivanovskii, A. L. Planar nano-block structures $\mathrm{Ti}_{n+1} \mathrm{Al}_{0.5} \mathrm{C}_{\mathrm{n}}$ and $\mathrm{Ti}_{\mathrm{n}+1} \mathrm{C}_{n}(\mathrm{n}=1$, and 2) from MAX phases: Structural, electronic properties and relative stability from first principles calculations. Superlattices Microstruct. 52, 147-157 (2012).

71. Xie, Y. et al. Role of Surface Structure on Li-Ion Energy Storage Capacity of TwoDimensional Transition-Metal Carbides. J. Am. Chem. Soc. 136, 6385-6394 (2014).

72. Yu, Y.-X. Prediction of Mobility, Enhanced Storage Capacity, and Volume Change during Sodiation on Interlayer-Expanded Functionalized $\mathrm{Ti}_{3} \mathrm{C}_{2}$ MXene Anode Materials for Sodium-Ion Batteries. J. Phys. Chem. C 120, 5288-5296 (2016).

73. Ji, X. et al. Probing the Electrochemical Capacitance of MXene Nanosheets for Highperformance Pseudocapacitors. Phys. Chem. Chem. Phys. 18, 4460-4467 (2016).

74. Zhang, X., Ma, Z., Zhao, X., Tang, Q. \& Zhou, Z. Computational Studies on Structural and Electronic Properties of Functionalized MXene Monolayers and Nanotubes. J. Mater. Chem. A 3, 4960-4966 (2015).

75. $\mathrm{Wu}, \mathrm{F}$. et al. Theoretical understanding of magnetic and electronic structures of $\mathrm{Ti}_{3} \mathrm{C}_{2}$ monolayer and its derivatives. Solid State Commun. 222, 9-13 (2015).

76. Tang, Q., Zhou, Z. \& Shen, P. Are MXenes promising anode materials for Li ion batteries? Computational studies on electronic properties and $\mathrm{Li}$ storage capability of $\mathrm{Ti}_{3} \mathrm{C}_{2}$ and $\mathrm{Ti}_{3} \mathrm{C}_{2} \mathrm{X}_{2}(\mathrm{X}$ = F, OH) monolayer. J. Am. Chem. Soc. 134, 16909-16916 (2012).

77. Li, X., Dai, Y., Ma, Y., Liu, Q. \& Huang, B. Intriguing electronic properties of twodimensional $\mathrm{MoS}_{2} / \mathrm{TM}_{2} \mathrm{CO}_{2}(\mathrm{TM}=\mathrm{Ti}, \mathrm{Zr}$, or Hf) hetero-bilayers: type-II semiconductors with tunable band gaps. Nanotechnology 26, 135703 (2015).

78. Hu, J., Xu, B., Ouyang, C. Y., Zhang, Y. \& Yang, S. Investigations on $\mathrm{Nb}_{2} \mathrm{C}$ Monolayer as Promising Anode Material for Li or Non-Li Ion Batteries from First-principles Calculations. RSC Adv. 6, 27467-27474 (2016).

79. Gandi, A. N., Alshareef, H. N. \& Schwingenschlögl, U. Thermoelectric Performance of the MXenes $\mathrm{M}_{2} \mathrm{CO}_{2}(\mathrm{M}=\mathrm{Ti}, \mathrm{Zr}$, or Hf). Chem. Mater. 28, 1647-1652 (2016).

80. Gan, L.-Y., Zhao, Y.-J., Huang, D. \& Schwingenschlögl, U. First-principles analysis of $\mathrm{MoS}_{2} / \mathrm{Ti}_{2} \mathrm{C}$ and $\mathrm{MoS}_{2} / \mathrm{Ti}_{2} \mathrm{CY}_{2}(\mathrm{Y}=\mathrm{F}$ and $\mathrm{OH})$ all-2D semiconductor/metal contacts. Phys. Rev. $B$ 87, 245307 (2013).

81. Eames, C. \& Islam, M. S. Ion Intercalation into Two-dimensional Transition-Metal Carbides: Global Screening for New High-Capacity Battery Materials. J. Am. Chem. Soc. 136, 16270-16276 (2014).

Comprehensive computational study of MXenes for different cations battery applications.

82. Berdiyorov, G. R., Madjet, M. E. \& Mahmoud, K. A. Ionic sieving through $\mathrm{Ti}_{3} \mathrm{C}_{2}(\mathrm{OH})_{2}$ MXene: First-principles calculations. Appl. Phys. Lett. 108, 113110 (2016).

83. Ashton, M., Hennig, R. G. \& Sinnott, S. B. Computational characterization of lightweight multilayer MXene Li-ion battery anodes. Appl. Phys. Lett. 108, 023901 (2016).

84. Ashton, M., Mathew, K., Hennig, R. G. \& Sinnott, S. B. Predicted Surface Composition and Thermodynamic Stability of MXenes in Solution. J. Phys. Chem. C 120, 3550-3556 (2016).

85. $\mathrm{Yu}, \mathrm{X}$.-f. et al. Monolayer $\mathrm{Ti}_{2} \mathrm{CO}_{2}$ : A Promising Candidate for $\mathrm{NH}_{3}$ Sensor or Capturer with High Sensitivity and Selectivity. ACS Appl. Mater. Interfaces 7, 13707-13713 (2015).

86. Wang, X. et al. Atomic-Scale Recognition of Surface Structure and Intercalation Mechanism of $\mathrm{Ti}_{3} \mathrm{C}_{2}$ X. J. Am. Chem. Soc. 137, 2715-2721 (2015).

87. Wang, H.-W., Naguib, M., Page, K., Wesolowski, D. J. \& Gogotsi, Y. Resolving the Structure of $\mathrm{Ti}_{3} \mathrm{C}_{2} \mathrm{~T}_{\mathrm{x}}$ MXenes through Multi-Level Structural Modeling of the Atomic Pair Distribution Function. Chem. Mater. 28, 349-359 (2015). 
88. Halim, J. et al. X-ray photoelectron spectroscopy of select multi-layered transition metal carbides (MXenes). Appl. Surf. Sci. 362, 406-417 (2016).

89. Enyashin, A. \& Ivanovskii, A. Atomic structure, comparative stability and electronic properties of hydroxylated $\mathrm{Ti}_{2} \mathrm{C}$ and $\mathrm{Ti}_{3} \mathrm{C}_{2}$ nanotubes. Comp. Theor. Chem. 989, 27-32 (2012).

90. Magne, D., Mauchamp, V., Célérier, S., Chartier, P. \& Cabioc'h, T. Spectroscopic evidence in the visible-ultraviolet energy range of surface functionalization sites in the multilayerTi $\mathrm{C}_{2}$ MXene. Phys. Rev. B 91, 201409 (2015).

91. Li, L. Lattice dynamics and electronic structures of $\mathrm{Ti}_{3} \mathrm{C}_{2} \mathrm{O}_{2}$ and $\mathrm{Mo}_{2} \mathrm{TiC}_{2} \mathrm{O}_{2}$ (MXenes): The effect of Mo substitution. Comput. Mater. Sci. 124, 8-14 (2016).

92. Khazaei, M., Ranjbar, A., Arai, M. \& Yunoki, S. Topological insulators in ordered double transition metals $\mathrm{M}_{2}^{\prime} \mathrm{M}^{\prime \prime} \mathrm{C}_{2}\left(\mathrm{M}^{\prime}=\mathrm{Mo}, \mathrm{W} ; \mathrm{M}^{\prime \prime}=\mathrm{Ti}, \mathrm{Zr}\right.$, Hf) MXenes. Phys. Rev. $B$ In Press (2016).

93. Harris, K. J., Bugnet, M., Naguib, M., Barsoum, M. W. \& Goward, G. R. Direct Measurement of Surface Termination Groups and Their Connectivity in the 2D MXene $\mathrm{V}_{2} \mathrm{CT}_{\mathrm{x}}$ Using NMR Spectroscopy. J. Phys. Chem. C 119, 13713-13720 (2015).

94. Hope, M. A. et al. NMR Reveals the Surface Functionalisation of $\mathrm{Ti}_{3} \mathrm{C}_{2}$ MXene. Phys. Chem. Chem. Phys. 18, 5099-5102 (2016).

95. Mashtalir, O. et al. The effect of hydrazine intercalation on structure and capacitance of 2D titanium carbide (MXene). Nanoscale 8, 9128-9133 (2016).

96. Ying, Y. et al. Two-Dimensional Titanium Carbide for Efficiently Reductive Removal of Highly Toxic Chromium (VI) from Water. ACS Appl. Mater. Interfaces 7, 1795-1803 (2015).

97. Peng, Y.-Y. et al. All-MXene (2D titanium carbide) solid-state microsupercapacitors for onchip energy storage. Energy Environ. Sci. 9, 2847-2854 (2016).

98. Mashtalir, O. et al. Dye adsorption and decomposition on two-dimensional titanium carbide in aqueous media. J. Mater. Chem. A 2, 14334-14338 (2014).

99. Wang, K. et al. Fabrication and thermal stability of two-dimensional carbide $\mathrm{Ti}_{3} \mathrm{C}_{2}$ nanosheets. Ceram. Int. 42, 8419-8424 (2016).

100. Naguib, M. et al. One-step synthesis of nanocrystalline transition metal oxides on thin sheets of disordered graphitic carbon by oxidation of MXenes. Chem. Commun. 50, 7420-7423 (2014).

101. Rakhi, R., Ahmed, B., Hedhili, M., Anjum, D. H. \& Alshareef, H. Effect of post-etch annealing gas composition on the structural and electrochemical properties of $\mathrm{Ti}_{2} \mathrm{CT}_{\mathrm{x}}$ MXene electrodes for supercapacitor applications. Chem. Mater. 27, 5314-5323 (2015).

102. Wang, H. et al. Enhancement of the electrical properties of MXene $\mathrm{Ti}_{3} \mathrm{C}_{2}$ nanosheets by post-treatments of alkalization and calcination. Mater. Lett. 160, 537-540 (2015).

103. Ghassemi, H. et al. In situ environmental transmission electron microscopy study of oxidation of two-dimensional $\mathrm{Ti}_{3} \mathrm{C}_{2}$ and formation of carbon-supported $\mathrm{TiO}_{2}$. J. Mater. Chem. A 2, 14339 (2014).

104. Naguib, M. MXenes: A New Family of Two-Dimensional Materials and its Application as Electrodes for Li-ion Batteries, PhD Thesis, Drexel University, (2014).

105. Lee, Y., Cho, S. B. \& Chung, Y. C. Tunable indirect to direct band gap transition of monolayer $\mathrm{Sc}_{2} \mathrm{CO}_{2}$ by the strain effect. ACS Appl. Mater. Interfaces 6, 14724-14728 (2014).

106. Ma, Z. et al. Tunable Band Structures of Heterostructured Bilayers with Transition-Metal Dichalcogenide and MXene Monolayer. J. Phys. Chem. C 118, 5593-5599 (2014).

107. Zhao, S., Kang, W. \& Xue, J. Manipulation of electronic and magnetic properties of $\mathrm{M}_{2} \mathrm{C}$ $(\mathrm{M}=\mathrm{Hf}, \mathrm{Nb}, \mathrm{Sc}, \mathrm{Ta}, \mathrm{Ti}, \mathrm{V}, \mathrm{Zr})$ monolayer by applying mechanical strains. Appl. Phys. Lett. 104, 133106 (2014).

108. Si, C., Zhou, J. \& Sun, Z. Half-metallic Ferromagnetism and Surface Functionalizationinduced Metal-insulator Transition in Graphene-like Two-dimensional $\mathrm{Cr}_{2} \mathrm{C}$ Crystals. ACS Appl. Mater. Interfaces 7, 17510-17515 (2015).

109. Weng, H. et al. Large-gap two-dimensional topological insulator in oxygen functionalized MXene. Phys. Rev. B 92, 075436 (2015).

110. Zhao, S., Kang, W. \& Xue, J. MXene nanoribbons. J. Mater. Chem. C 3, 879-888 (2015). 
111. Yang, J., Luo, X., Zhang, S. \& Chen, L. Investigation of magnetic and electronic properties of transition metal doped $\mathrm{Sc}_{2} \mathrm{CT}_{2}(\mathrm{~T}=\mathrm{O}, \mathrm{OH}$ or $\mathrm{F})$ using a first principles study. Phys. Chem. Chem. Phys. 18, 12914-12919 (2016).

112. Mauchamp, V. et al. Enhanced and tunable surface plasmons in two-dimensional $\mathrm{Ti}_{3} \mathrm{C}_{2}$ stacks: Electronic structure versus boundary effects. Phys. Rev. B 89, 235428 (2014).

113. Borysiuk, V. N., Mochalin, V. N. \& Gogotsi, Y. Molecular dynamic study of the mechanical properties of two-dimensional titanium carbides $\mathrm{Ti}_{\mathrm{n}+1} \mathrm{C}_{\mathrm{n}}$ (MXenes). Nanotechnology 26, 265705 (2015).

114. Fu, Z. et al. Stabilization and strengthening effects of functional groups in two-dimensional titanium carbide. Phys. Rev. B 94, 104103 (2016).

115. Yorulmaz, U., Özden, A., Perkgöz, N. K., Ay, F. \& Sevik, C. Vibrational and mechanical properties of single layer MXene structures: a first-principles investigation. Nanotechnology 27, 335702 (2016).

116. Zhang, H. et al. Computational studies on the structural, electronic and optical properties of graphene-like MXenes (M 2 CT 2, M= Ti, Zr, Hf; T= O, F, OH) and their potential applications as visible-light driven photocatalysts. J. Mater. Chem. A 4, 12913-12920 (2016).

117. Ling, Z. et al. Flexible and conductive MXene films and nanocomposites with high capacitance. Proc. Natl. Acad. Sci. 111, 16676-16681 (2014).

118. Boota, M. et al. Pseudocapacitive Electrodes Produced by Oxidant-Free Polymerization of Pyrrole between the Layers of 2D Titanium Carbide (MXene). Adv. Mater. 28, 1517-1522 (2016). 119. Zhang, H. et al. Preparation, mechanical and anti-friction performance of MXene/polymer composites. Mater. Des. 92, 682-689 (2016).

120. Wu, X. et al. Polymer- $\mathrm{Ti}_{3} \mathrm{C}_{2} \mathrm{~T}_{\mathrm{x}}$ composite membranes to overcome the trade-off in solvent resistant nanofiltration for alcohol-based system. J. Membr. Sci. 515, 175-188 (2016).

121. Zhao, M.-Q. et al. Flexible MXene/Carbon Nanotube Composite Paper with High Volumetric Capacitance. Adv. Mater. 27, 339-345 (2015).

122. Liu, Y., Wang, W., Ying, Y., Wang, Y. \& Peng, X. Binder-free layered $\mathrm{Ti}_{3} \mathrm{C}_{2} / \mathrm{CNTs}$ nanocomposite anodes with enhanced capacity and long-cycle life for lithium-ion batteries. Dalton Trans. 44, 7123-7126 (2015).

123. Dall'Agnese, Y., Rozier, P., Taberna, P.-L., Gogotsi, Y. \& Simon, P. Capacitance of twodimensional titanium carbide (MXene) and MXene/carbon nanotube composites in organic electrolytes. J. Power Sources 306, 510-515 (2016).

124. Dillon, A. D. et al. Highly Conductive Optical Quality Solution - Processed Films of 2D Titanium Carbide. Adv. Funct. Mater. 26, 4162-4168 (2016).

125. Hantanasirisakul, K. et al. Fabrication of $\mathrm{Ti}_{3} \mathrm{C}_{2} \mathrm{~T}_{\mathrm{x}}$ MXene Transparent Thin Films with Tunable Optoelectronic Properties. Adv. Electron. Mater. 2, 1600050 (2016).

126. Zha, X.-H. et al. Role of the surface effect on the structural, electronic and mechanical properties of the carbide MXenes. Europhys. Lett. 111, 26007 (2015).

127. Fashandi, H. et al. Dirac points with giant spin-orbit splitting in the electronic structure of two-dimensional transition-metal carbides. Phys. Rev. B 92, 155142 (2015).

128. Miranda, A., Halim, J., Barsoum, M. \& Lorke, A. Electronic properties of freestanding $\mathrm{Ti}_{3} \mathrm{C}_{2} \mathrm{~T}_{\mathrm{x}}$ MXene monolayers. Appl. Phys. Lett. 108, 033102 (2016).

129. Paton, K. R. et al. Scalable production of large quantities of defect-free few-layer graphene by shear exfoliation in liquids. Nat. Mater. 13, 624-630 (2014).

130. Parvez, K. et al. Electrochemically exfoliated graphene as solution-processable, highly conductive electrodes for organic electronics. ACS Nano 7, 3598-3606 (2013).

131. Lane, N. J., Barsoum, M. W. \& Rondinelli, J. M. Correlation effects and spin-orbit interactions in two-dimensional hexagonal $5 \mathrm{~d}$ transition metal carbides, $\mathrm{Ta}_{\mathrm{n}+1} \mathrm{C}_{\mathrm{n}}(\mathrm{n}=1,2,3)$. Europhys. Lett. 101, 57004 (2013).

132. Wang, G. A Theoretical Prediction of the Intrinsic Half-Metallicity in Surface-OxygenPassivated $\mathrm{Cr}_{2} \mathrm{~N}$ MXene. J. Phys. Chem. C (2016). 
133. Bonaccorso, F. et al. Graphene, related two-dimensional crystals, and hybrid systems for energy conversion and storage. Science 347, 1246501 (2015).

134. Feng, F., Wu, J., Wu, C. \& Xie, Y. Regulating the electrical behaviors of 2D inorganic nanomaterials for energy applications. Small 11, 654-666 (2015).

135. Naguib, M. et al. MXene: a promising transision metal carbide anode for Lithium-ion batteries. Electrochem. Commun. 16, 61-64 (2012).

136. Xie, Y. et al. Prediction and characterization of MXene nanosheet anodes for non-lithiumion batteries. ACS Nano 8, 9606-9615 (2014).

137. Sun, D. et al. Structural Transformation of MXene $\left(\mathrm{V}_{2} \mathrm{C}, \mathrm{Cr}_{2} \mathrm{C}\right.$, and $\left.\mathrm{Ta}_{2} \mathrm{C}\right)$ with $\mathrm{O}$ Groups during Lithiation: A First-Principles Investigation. ACS Appl. Mater. Interfaces 8, 74-81 (2015).

138. Ren, C. E. et al. Porous Two - Dimensional Transition Metal Carbide (MXene) Flakes for High - Performance Li - Ion Storage. ChemElectroChem 3, 689-693 (2016).

139. Wang, X. et al. Pseudocapacitance of MXene nanosheets for high-power sodium-ion hybrid capacitors. Nat. Commun. 6, 6544, 6544 (2015).

The first report on MXene application in sodium-ion hybrid capacitors.

140. Dall'Agnese, Y., Taberna, P. L., Gogotsi, Y. \& Simon, P. Two-Dimensional Vanadium Carbide (MXene) as Positive Electrode for Sodium-Ion Capacitors. J. Phys. Chem. Lett. 6, 23052309 (2015).

141. $\mathrm{Yu}, \mathrm{X}$.-f. et al. $\mathrm{Mg}$ intercalation into $\mathrm{Ti}_{2} \mathrm{C}$ building block. Chem. Phys. Lett. 629, 36-39 (2015).

142. Liang, X., Garsuch, A. \& Nazar, L. F. Sulfur Cathodes Based on Conductive MXene Nanosheets for High-Performance Lithium-Sulfur Batteries. Angew. Chem. 54, 3907-3911 (2015).

First report on use of MXenes in lithium-sulfur batteries.

143. Zhao, X. et al. Fabrication of layered $\mathrm{Ti}_{3} \mathrm{C}_{2}$ with an accordion-like structure as a potential cathode material for high performance lithium-sulfur batteries. J. Mater. Chem. A 3, 7870-7876 (2015).

144. Luo, J. et al. $\mathrm{Sn}^{4+}$ Ion Decorated Highly Conductive $\mathrm{Ti}_{3} \mathrm{C}_{2}$ MXene: Promising Lithium-Ion Anodes with Enhanced Volumetric Capacity and Cyclic Performance. ACS Nano 10, 2491-2499 (2016).

145. Lukatskaya, M. R. et al. Cation Intercalation and High Volumetric Capacitance of TwoDimensional Titanium Carbide. Science 341, 1502-1505 (2013).

This is the first demonstration of MXene being able to host a variety of cations such as $\mathrm{Na}^{+}, \mathrm{K}^{+}$, $\mathrm{NH}_{4}^{+}, \mathrm{Mg}^{2+}, \mathrm{Al}^{3+}$, enabling their use in supercapacitors.

146. Come, J. et al. Controlling the actuation properties of MXene paper electrodes upon cation intercalation. Nano Energy 17, 27-35 (2015).

147. Levi, M. D. et al. Solving the Capacitive Paradox of 2D MXene using Electrochemical Quartz-Crystal Admittance and In Situ Electronic Conductance Measurements. Adv. Energy Mater. 5, 1400815 (2015).

148. Tao, Y. et al. Towards ultrahigh volumetric capacitance: graphene derived highly dense but porous carbons for supercapacitors. Sci. Rep. 3, 2975 (2013).

149. Shen, B.-S. et al. All-solid-state flexible microsupercapacitor based on two-dimensional titanium carbide. Chin. Chem. Lett. 27, 1586-1591 (2016).

150. Lukatskaya, M. R. et al. Probing the Mechanism of High Capacitance in 2D Titanium Carbide Using In Situ X-Ray Absorption Spectroscopy. Adv. Energy Mater. 5, 1500589 (2015).

151. Dall'Agnese, Y. et al. High capacitance of surface-modified 2D titanium carbide in acidic electrolyte. Electrochem. Commun. 48, 118-122 (2014).

152. Lin, Z. et al. Capacitance of $\mathrm{Ti}_{3} \mathrm{C}_{2} \mathrm{~T}_{\mathrm{x}}$ MXene in ionic liquid electrolyte. J. Power Sources 326, 575-579 (2016). 
153. Peng, Q. et al. Unique lead adsorption behavior of activated hydroxyl group in twodimensional titanium carbide. J. Am. Chem. Soc. 136, 4113-4116 (2014).

154. Xie, X. et al. Surface Al Leached $\mathrm{Ti}_{3} \mathrm{AlC}_{2}$ Substituting Carbon for Catalyst Support Served in a Harsh Corrosive Electrochemical System. Nanoscale 6, 11035-11040 (2014).

155. Liu, H. et al. A novel nitrite biosensor based on the direct electrochemistry of hemoglobin immobilized on MXene-Ti ${ }_{3} \mathrm{C}_{2}$. Sens. Actuator B-Chem. 218, 60-66 (2015).

156. Zhang, $\mathrm{X}$. et al. Preparation and tribological properties of $\mathrm{Ti}_{3} \mathrm{C}_{2}(\mathrm{OH})_{2}$ nanosheets as additives in base oil. RSC Adv. 5, 2762-2767 (2015).

157. Xuan, J. et al. Organic - Base - Driven Intercalation and Delamination for the Production of Functionalized Titanium Carbide Nanosheets with Superior Photothermal Therapeutic Performance. Angew. Chem. (2016).

158. Chen, J. et al. $\mathrm{CO}_{2}$ and temperature dual responsive "Smart" MXene phases. Chem. Commun. 51, 314-317 (2015).

159. Qing, Y., Zhou, W., Luo, F. \& Zhu, D. Titanium carbide (MXene) nanosheets as promising microwave absorbers. Ceram. Int. 42, 16412-16416 (2016).

160. Han, M. et al. $\mathrm{Ti}_{3} \mathrm{C}_{2}$ MXenes with Modified Surface for High-Performance Electromagnetic Absorption and Shielding in the X-Band. ACS Appl. Mater. Interfaces 8, 21011-21019 (2016).

161. Zou, G. et al. Synthesis of urchin-like rutile titania carbon nanocomposites by ironfacilitated phase transformation of MXene for environmental remediation. J. Mater. Chem. A 4, 489-499 (2016).

162. Guo, J., Peng, Q., Fu, H., Zou, G. \& Zhang, Q. Heavy-Metal Adsorption Behavior of TwoDimensional Alkalization-Intercalated MXene by First-Principles Calculations. J. Phys. Chem. C 119, 20923-20930 (2015).

163. Zhang, Q. et al. Efficient Phosphate sequestration for water purification by Unique Sandwich-like MXene/Magnetic Iron Oxide Nanocomposites. Nanoscale 8, 7085-7093 (2016).

164. Ren, C. E. et al. Charge- and Size-Selective Ion Sieving Through $\mathrm{Ti}_{3} \mathrm{C}_{2} \mathrm{~T}_{\mathrm{x}} \mathrm{MXene}$ Membranes. J. Phys. Chem. Lett. 6, 4026-4031 (2015).

165. Zhang, Y.-J. et al. Adsorption of Uranyl Species on Hydroxylated Titanium Carbide Nanosheet: A First-Principles Study. J. Hazard. Mater. 308, 402-410 (2016).

166. Wang, L. et al. Loading actinides in multi-layered structures for nuclear waste treatment: the first case study of uranium capture with vanadium carbide MXene. ACS Appl. Mater. Interfaces 8, 16396-16403 (2016).

167. Xiao, B., Li, Y.-c., Yu, X.-f. \& Cheng, J.-b. MXenes: Reusable materials for $\mathrm{NH}_{3}$ sensor or capturer by controlling the charge injection. Sens. Actuator B-Chem. 235, 103-109 (2016).

168. Zhang, X. et al. Ti-Anchored $\mathrm{Ti}_{2} \mathrm{CO}_{2}$ Monolayer (MXene) as a Single-Atom Catalyst for $\mathrm{CO}$ Oxidation. J. Mater. Chem. A 4, 4871-4876 (2016).

169. Tian Yi Ma, Jian Liang Cao, Mietek Jaroniec \& Qiao, S. Z. Interacting Carbon Nitride and Titanium Carbide Nanosheets for High-Performance Oxygen Evolution. Angew. Chem. 127, 3 (2015).

170. Li, X., Zeng, C. \& Fan, G. Ultrafast hydrogen generation from the hydrolysis of ammonia borane catalyzed by highly efficient bimetallic RuNi nanoparticles stabilized on $\mathrm{Ti}_{3} \mathrm{C}_{2} \mathrm{X}_{2}(\mathrm{X}=\mathrm{OH}$ and/or F). Int. J. Hydrogen Energy 40, 3883-3891 (2015).

171. Gao, Y. et al. Preparation of $\mathrm{MXene}-\mathrm{Cu}_{2} \mathrm{O}$ nanocomposite and effect on thermal decomposition of ammonium perchlorate. Solid State Sci. 35, 62-65 (2014).

172. Peng, C. et al. Hybrids of Two-Dimensional $\mathrm{Ti}_{3} \mathrm{C}_{2}$ and $\mathrm{TiO}_{2}$ Exposing $\{001\}$ Facets toward Enhanced Photocatalytic Activity. ACS Appl. Mater. Interfaces 8, 6051-6060 (2016).

173. Azofra, L. M., Li, N., MacFarlane, D. R. \& Sun, C. Promising prospects for $2 \mathrm{D} \mathrm{d} \mathrm{d}^{2}-\mathrm{d}^{4} \mathrm{M}_{3} \mathrm{C}_{2}$ transition metal carbides (MXenes) in $\mathrm{N}_{2}$ capture and conversion into ammonia. Energy Environ. Sci. 9, 2545-2549 (2016).

174. Xu, B. et al. Ultrathin MXene-Micropattern-Based Field-Effect Transistor for Probing Neural Activity. Adv. Mater. 28, 3333-3339 (2016). 
175. Rasool, K. et al. Antibacterial Activity of $\mathrm{Ti}_{3} \mathrm{C}_{2} \mathrm{~T}_{\mathrm{x}}$ MXene. ACS Nano 10, 3674-3684 (2016).

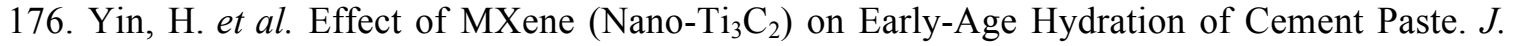
Nanomater. 16, 147 (2015).

177. Yang, J., Chen, B., Song, H., Tang, H. \& Li, C. Synthesis, characterization, and tribological properties of two-dimensional $\mathrm{Ti}_{3} \mathrm{C}_{2}$. Cryst. Res. Technol. 49, 926-932 (2014).

\section{Subject terms}

Physical sciences / Materials science / Nanoscale materials / Two-dimensional materials [URI /639/301/357/1018]

Physical sciences / Materials science / Condensed-matter physics / Semiconductors / Twodimensional materials

[URI /639/301/119/1000/1018]

Physical sciences / Materials science / Materials for energy and catalysis / Batteries [URI $/ 639 / 301 / 299 / 891]$

Physical sciences / Materials science / Materials for energy and catalysis / Electrochemistry / Batteries

[URI /639/301/299/161/891] 